\title{
Supply Chain Risk Management and Artificial Intelligence: State of the Art and Future Research Directions
}

\author{
George Baryannis $^{\mathrm{a} *}$, Sahar Validi ${ }^{\mathrm{b}}$, Samir Dani ${ }^{\mathrm{b}}$ and Grigoris Antoniou ${ }^{\mathrm{a}}$ \\ ${ }^{a}$ Department of Computer Science, School of Computing \& Engineering, University of \\ Huddersfield, Huddersfield, UK; ${ }^{b}$ Department of Logistics, Operations, Hospitality and \\ Marketing, Huddersfield Business School, University of Huddersfield, Huddersfield, UK
}

\begin{abstract}
Supply Chain Risk Management (SCRM) encompasses a wide variety of strategies aiming to identify, assess, mitigate and monitor unexpected events or conditions which might have an impact, mostly adverse, on any part of a supply chain. SCRM strategies often depend on rapid and adaptive decision making based on potentially large, multidimensional data sources. These characteristics make SCRM a suitable application area for Artificial Intelligence (AI) techniques. The aim of this paper is to provide a comprehensive review of supply chain literature that addresses problems relevant to SCRM using approaches that fall within the AI spectrum. To that end, an investigation is conducted on the various definitions and classifications of supply chain risk and related notions such as uncertainty. Then, a mapping study is performed to categorise existing literature according to the AI methodology used, ranging from mathematical programming to Machine Learning and Big Data Analytics, and the specific SCRM task they address (identification, assessment or response). Finally, a comprehensive analysis of each category is provided to identify missing aspects and unexplored areas and propose directions for future research at the confluence of SCRM and AI.
\end{abstract}

\section{KEYWORDS}

supply chain risk management; artificial intelligence; decision making; SCRM

strategy; supply chain disruption

\section{Introduction}

Supply chains, especially global ones, have always been affected by predictable or unforeseen events that threaten their profitability and continuity. Practitioners and researchers have, thus, been interested in investigating the causes of these events in an attempt to mitigate the effects of the associated risks. This interest has increased significantly over the past two decades for three main reasons. First, the adoption of lean management and just-in-time philosophy in production and logistics may have increased efficiency but have left supply chains vulnerable to adverse events since they leave little room for error and change (Snyder et al. 2016). Second, firms are increasingly global and less vertically integrated, increasing the complexity of supply chains and exposing them to much more risks (Behzadi et al. 2018). Third, numerous events have been witnessed to disrupt global supply chains and have attracted worldwide attention. These range from natural disasters, such as the 2011 Thailand floods which caused a global shortage of hard disk drives (Chopra and Sodhi 2014), to man-made

\footnotetext{
*Corresponding author. Email: g.bargiannis@hud.ac.uk
} 
disasters such as the 9/11 terrorist attacks. They also include events that cause financial or political instability, such as the 2008 global financial crisis (World Economic Forum 2012) and the subsequent Great Recession or the decision in 2016 of the UK to withdraw from the European Union (Brexit) (Matthews 2017).

Research in supply chain risk management (SCRM) has included many different methodologies, from qualitative ones such as empirical studies and conceptual theories to quantitative approaches such as mathematical optimisation, statistics and simulation (Ghadge, Dani, and Kalawsky 2012). In terms of implemented strategies, SCRM can follow either a reactive or a proactive strategy: the former is applied after a risk materialises, while the latter allows to identify and assess risks before they occur, in order to prepare suitable mitigation and contingency plans. Experience drawn from cases such as the Philips/Ericsson one in 2000 (Norrman and Jansson 2004) led researchers to place more focus on proactive strategies since delayed risk responses have proven to be significantly damaging. Recent events such as the KFC chicken supply crisis in early 2018 (Green 2018) strengthen the view that weighing risks and preparing contingency plans ahead of a major switch in a supply chain can potentially prevent significant losses. To achieve this, proactive strategies rely on the ability to accurately predict the likelihood of occurrence and the potential impact of risks. This necessary predictive capability can be achieved using techniques that fall within the broad spectrum of Artificial Intelligence (AI).

AI research has had a long history since the creation of the Turing Test in 1950 and the naming of the field at the 1956 Dartmouth workshop (Solomonoff 1985). Interest in the field has seen wide variations, from periods of relatively low interest (known as AI winters) to periods of resurgence and rapid progress. Starting in the early 2000s, increasing computing power and advances in Big Data and Machine Learning research have led to renewed interest in AI, going as far as being termed "the AI frenzy" in the media (Lohr 2016), spearheaded by recent successes of systems such as IBM Watson ${ }^{1}$ and DeepMind's AlphaGo 2 . This resurgence has also led to AI being considered in research areas and applications where it has not played an important role in the past (such as human resources and recruitment (Zhao et al. 2015)), or in areas where classic AI techniques have been applied but more recent advances have not been explored. This survey aims to contribute to the latter case.

Methodologies and techniques that fall under the umbrella of AI are numerous. For the purposes of this survey, a classification into five broad categories is adopted: (1) techniques that rely on some form of mathematical optimisation; (2) network-based approaches that represent problems as sets of possible states and transitions among them; (3) methodologies that adopt agent-based modelling and multi-agent system interactions; (4) approaches that involve some form of automated reasoning based on existing knowledge; and (5) machine learning and big data analytics techniques. Exploiting these techniques can lead to several interesting applications in the field of SCRM, including, but not limited to, risk-aware automated supplier selection, risk propagation modelling in a supply network, identification and prediction of deceptive supply chain practices, data-driven explanation of disaster resilience, and end-to-end decision support to facilitate collaborative disruption management.

The main purpose of this paper is to conduct a comprehensive review of SCRMrelated studies that involve AI methodologies to achieve their goals, essentially answering the following research question: to what extent has research in the field of

\footnotetext{
${ }^{1}$ https://www.ibm.com/watson/

${ }^{2}$ https://deepmind.com/research/alphago/
} 
SCRM exploited AI capabilities such as decision making, prediction, learning and ability to deal with complex and uncertain environments? In order to effectively answer this question, a critical comparison and assessment of relevant literature is conducted through answering the following sub-questions for each reviewed study:

(1) Is any decision-making capability provided and has it been applied to influence SCRM-related decisions?

(2) Is any predictive capability provided, with regard to future situations that affect the supply chain in terms of risk?

(3) Is any learning capability provided, adapting decisions according to updated knowledge?

(4) How many risk-related (or uncertain) parameters are considered?

(5) Are large datasets exploited?

(6) Which SCRM-related tasks (e.g. identification, assessment, response) are realised?

Several literature reviews on topics relevant to SCRM have been published in recent years ${ }^{3}$. However, to the best of the authors' knowledge, there has not been any attempt to view SCRM literature under the prism of AI and assess how effectively SCRM research has exploited the potential of AI techniques. In this context, the main contributions of this survey are:

- A comprehensive analysis of SCRM literature, in terms of AI-related capabilities, namely decision making, prediction and learning

- An investigation on the extent to which large datasets are exploited by existing SCRM approaches

- A correlation between AI-related methodologies and the SCRM tasks on which they are applied

- A detailed identification of research gaps and relevant future directions aiming to harness the untapped potential of current advancements in AI research for the benefit of SCRM

As succinctly presented in Olhager (2013), production research and especially planning and control, has witnessed several paradigm shifts since the 1960s, moving from a shop floor level to enterprise resource planning and eventually supply chain-wide decision making. It can be argued that AI has gradually brought about a new paradigm shift, leading to automated systems that can harness knowledge and data to improve decision making within supply chains. This survey contributes to understanding the progression of this shift so far, in what concerns SCRM, and mapping the way forward.

The remainder of this paper is organised as follows. Section 2 offers a concise analysis of risk, uncertainty and related notions and provides the definitions of SCRM and AI based on which this survey is constructed. Section 3 presents the methodology followed for the review, also providing a comparison to related survey papers in literature. Section 4 contains a classification analysis of the reviewed studies, according to publication year and venue, case studies and types of risk and uncertainty. Section 5 is the main part of the survey, answering the aforementioned research questions by evaluating the reviewed studies in terms of their AI capabilities and the SCRM tasks they realise. Finally, Section 6 discusses a set of research gaps that result from this survey and proposes several interesting directions for future research.

\footnotetext{
${ }^{3}$ For a detailed analysis of relevant literature, please refer to Section 3.3
} 


\section{Background of Study}

This section is devoted to analysing the background knowledge relevant to this literature review. It begins with a series of definitions on supply chain risk, uncertainty and related notions, as well as SCRM, based on a meta-review conducted on previously published survey and research agenda articles on supply chain risk. Then, a definition of $\mathrm{AI}$ is provided that is relevant for the purposes of this survey.

\subsection{Risk and Uncertainty}

While there have been several attempts to define supply chain risk, there is no universally accepted definition. Early attempts to define risk in SCRM literature relied on existing definitions in finance and enterprise risk management. For instance, Jüttner (2005) assumes March and Shapira's definition of risk as "the variation in the distribution of possible outcomes, their likelihoods, and their subjective value" (March and Shapira 1987). Risk definitions tend to be vague and ambiguous, involving a wide array of core characteristics (Heckmann, Comes, and Nickel 2015). Among the various proposals, there has been consensus on some characteristics of risks. Specifically, there is an agreement that risk involves exposure to an event (Holton 2004), which occurs with varying likelihood and possible outcomes (Manuj and Mentzer 2008a).

On the other hand, there has been extensive debate on whether risk is a subjective or objective phenomenon, whether it involves both negative and positive outcomes, and the relation of risk and uncertainty (Khan and Burnes 2007). Those in favour of a subjective view argue that a risk is determined by the viewpoints (social, political or otherwise) of the stakeholders involved, while others maintain that risk is objectively defined based on quantifiable and measurable dimensions (Lupton 2013). In terms of outcomes, risk is more commonly associated with the negative consequences (i.e. losses) that follow an event occurrence, with relatively fewer researchers stressing the positive effects (i.e. gains) that may be possible in a risky situation.

On the connection between risk and uncertainty, Manuj and Mentzer (2008b) view risk as the expected outcome of an uncertain event, while Rao and Goldsby (2009) link a risk to an event and the uncertainty of possible outcomes. Vilko, Ritala, and Edelmann (2014) model a complete spectrum of the knowledge that decision makers hold about the supply chain, ranging from complete certainty to radical uncertainty. In between, there are four distinct stages of increasing levels of uncertainty; the closest one to complete certainty is the one that the authors view as a basis for typical SCRM: the situation where the supply chain structure is fully known and the likelihood and impact of future events is known in terms of objective probabilities. This is in contrast to the next more uncertain level where these probabilities are not known and SCRM can only rely on subjective beliefs.

In the context of managing supply chain risks, the aforementioned debates can be resolved in order to obtain a more specific risk definition. First, SCRM can certainly benefit from an objective rather than a subjective view, provided that the focus is on wider applicability instead of individualised approaches. Second, the concept of managing risks carries the connotation of adverse effects, in the sense of containing or avoiding altogether the negative consequences accompanying risk. Finally, SCRM is only effective when at least the supply chain structure is fully known. A recent risk definition that captures these characteristics is provided by Ho et al. (2015), where supply chain risk is defined as "the likelihood and impact of unexpected macro and/or 
micro-level events or conditions that adversely influence any part of a supply chain, leading to operational, tactical or strategic level failures or irregularities".

\section{2. $\quad$ Related notions}

While risk and uncertainty are the most common terms used in association with SCRM in literature, there are several related notions that usually stress either negative consequences of risk or positive outcomes of managing risk. A summary of definitions for some of these notions follows, based on relevant discussions that have appeared in SCRM literature.

Vulnerability and disturbance are frequently used by researchers and practitioners to describe a supply chain affected by risk. Both Jüttner (2005) and Martin and Peck (2004) define vulnerability as an exposure to disturbances due to supply chain risks, affecting the ability to satisfy the end customer market needs. Disruption is a synonym of disturbance, albeit one with graver consequences: while disturbance may simply interrupt a normal situation, disruption causes a violent dissolution of continuity (Pfohl, Köhler, and Thomas 2010). As further analysed in Section 2.4. disruption has been widely used to denote risks caused by natural and man-made disasters. Other terms with negative connotations that have been used in relation to risk are threat, crisis, disaster, catastrophe, peril, hazard and emergency.

Other negative terms associated with risk are threat, which is either viewed as a synonym for risk, or as a lower probability event than risk (Schlegel and Trent 2014) and crisis, defined as "the interruption of one or more supply chain activities, resulting in a major disruption of the normal flow of goods or services" (Natarajarathinam, Capar, and Narayanan 2009).

In terms of positive outcomes, risk is often associated with robustness and resilience, which are usually viewed as means of decreasing supply chain vulnerability (Behzadi et al. 2018). Robustness is defined by Colicchia and Strozzi (2012) as "the extent to which the supply chain is able to carry its functions for a variety of possible future scenarios". Resilience puts more emphasis on the proactive ability to adapt in preparation for unexpected events so that it is possible to quickly recover from them and reinstate continuity of operations in the supply chain (Ponomarov and Holcomb 2009). Other terms with positive connotations that have appeared in literature relevant to risk are security, safety, sustainability, opportunity, flexibility and agility.

It should be noted that the aforementioned notions are all qualitative in nature. Risk is often quantified through a product of its probability and its impact, provided that these can be represented numerically. Alternatively, SCRM researchers have proposed the use of several measures, most of which are borrowed from research in financial risk management. Among them, the most commonly used are deviation-based, aiming to quantify risk in terms of how much it affects a situation compared to normal circumstances. Examples include variance, standard, absolute or expected deviation, or central semideviation. Another commonly used category includes the downside-risk measures of value-at-risk ( VaR) and conditional-value-at-risk (CVaR). VaR expresses a loss threshold given a specific probability, while CVaR expresses the average loss beyond that threshold. For a more detailed analysis of risk measures, please refer to Heckmann, Comes, and Nickel (2015) and Govindan, Fattahi, and Keyvanshokooh (2017). 


\subsection{Supply Chain Risk Management}

As is the case with risk, there is no universally accepted definition of SCRM. However, in contrast to risk, there seems to be more agreement than debate. Nearly all proposals define SCRM in terms of a set of actions that lead to an intended result, while also stressing out the prerequisite of coordination and collaboration among supply chain partners. SCRM-related actions are either collectively termed as management (e.g. (Jüttner 2005; Tang 2006)), or are individually specified. In the latter case, SCRM is defined to include identification (Jüttner 2005, Manuj and Mentzer 2008b), evaluation (Manuj and Mentzer 2008b; Ho et al. 2015), mitigation and monitoring (Ho et al. 2015) of risks.

In terms of intended results of SCRM, researchers either stress the mitigation of negative effects of risks or the strengthening of positive characteristics of the supply chain. Examples of the former case include reducing vulnerability (Jüttner 2005: Martin and Peck 2004), losses, probability or exposure to risks (Manuj and Mentzer 2008b). On the other hand, positive effects of SCRM that are included in definitions involve ensuring profitability and continuity (Tang 2006; Manuj and Mentzer 2008b).

For the purposes of this survey paper, an inclusive synthesis of the aforementioned elements is proposed, which results in the following generalised definition: SCRM encompasses the collaborative and coordinated efforts of all parties involved in a supply chain to identify, assess, mitigate and monitor risks with the aim to reduce vulnerability and increase robustness and resilience of the supply chain, ensuring profitability and continuity.

\subsection{Risk classification}

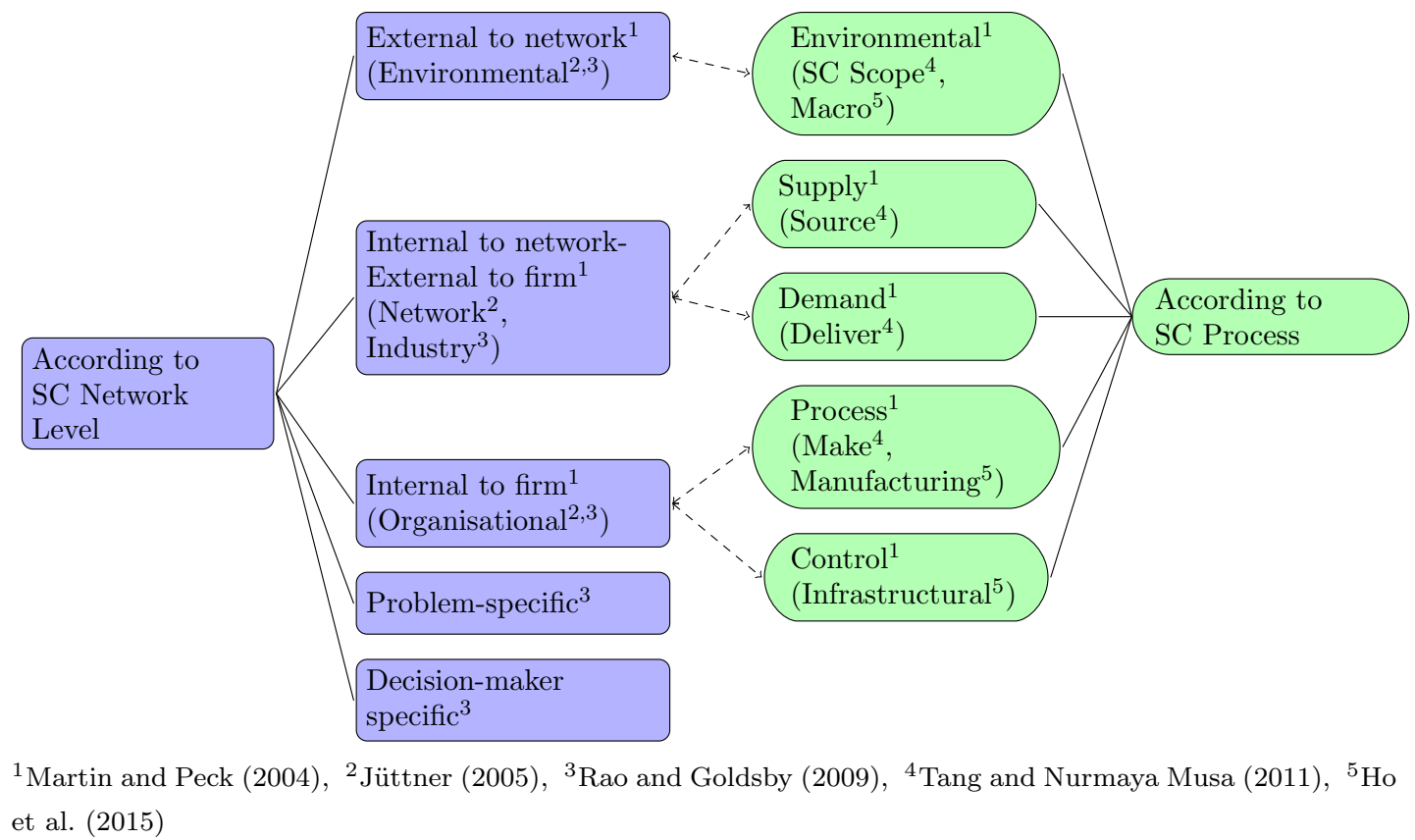

Figure 1.: Common supply chain risk classifications.

Risks have been classified in many different ways in SCRM literature, depending on the scope and goals of each research article (Rangel, de Oliveira, and Leite 2015 
Hudnurkar et al. 2017). The two most common supply chain risk classifications in literature are shown in Fig. 1. The first, shown on the left side, classifies risks according to the level within the supply chain network that they affect or are sourced from (Martin and Peck 2004, Jüttner 2005, Rao and Goldsby 2009). Three main levels are usually recognised. The first involves risks that are external to the network, alternatively termed environmental. The second level groups risks that are internal to the network but external to the focal firm, also named as network or industry risks. The third level includes all risks that are internal to the firm, called organisational. Rao and Goldsby (2009) recognise two additional levels related to the specific decision problem at hand and characteristics of individual decision makers.

An alternative risk classification approach is based on the specific subset of the supply chain that the risk affects or is sourced from (Martin and Peck 2004; Manuj and Mentzer 2008b; Peidro et al. 2009; Tang and Nurmaya Musa 2011; Ho et al. 2015), shown on the right side of Fig. 1]. Five separate classes are identified. The first involves risks that are related to the supply chain as a whole and not to any specific part of it; this category directly corresponds to the aforementioned first level (external to the network) and risks within are referred to as environmental (Martin and Peck 2004), macro (Ho et al. 2015) or SC scope (Tang and Nurmaya Musa 2011). The second class groups risks that are related to the supply side of the chain (or source, according to the SCOR model). On the other hand, the third class contains all demand side risks (deliver, according to SCOR). The fourth class involves risks that affect the supply chain processes, alternatively termed manufacturing (Ho et al. 2015) or make (Tang and Nurmaya Musa 2011) risks. The fifth and final class groups risks that relate tocontrol over supply chain processes (equivalent to the infrastructural risks in Ho et al. (2015)).

\subsection{Artificial Intelligence}

Ever since its introduction in the 1950s, the field of AI has witnessed alternating periods of intense growth and significant decline. In recent years, factors such as increasing computational power and availability of Big Data, among others, have led to renewed interest in the field. Due to this constant evolution in AI research, the definition of what is considered AI is also continually evolving.

Legg and Hutter (2007) have attempted a thorough analysis of well known definitions of intelligence in order to come up with a formalised definition and measure of Machine Intelligence. In their analysis, they identify two fundamental prerequisite features for considering a human or machine intelligent: (1) the ability to carefully choose their actions in a way that leads to success or profit, in terms of some kind of objective or goal; (2) the ability to deal not with a fully known environment, but with a range of possibilities which cannot be wholly anticipated, through learning and adaptation.

For the purposes of this survey, an SCRM approach is considered as artificially intelligent if it satisfies both of the aforementioned characteristics: it should be able to autonomously decide on a course of action that leads to success in SCRM-related objectives and do so under a partially unknown supply chain environment. The particular AI techniques that are exploited can range from traditional symbolic AI, relying on mathematical, or knowledge-based problem representations, to sub-symbolic AI, including, for instance, fuzzy systems and evolutionary computation, to statistical AI, encompassing Machine Learning approaches. 


\section{Review methodology}

\section{1. $\quad$ Search strategy}

The literature review conducted for the purposes of this paper relies primarily on automated search. Following recently published reviews (Fahimnia et al. 2015; Prakash, Soni, and Rathore 2017), two levels of keywords are used, conjunctively combined with AND. The first level defines the search context and includes the term "supply chain". The second level includes the following disjunction of terms related to risk and uncertainty, as detailed in Sections 2.1 and 2.2. "risk OR uncertainty OR vulnerability OR threat OR disruption OR disturbance OR crisis OR disaster OR catastrophe OR peril OR hazard OR emergency OR opportunity OR resilience OR robustness OR security OR safety OR flexibility OR agility OR sustainability".

Bibliometric research (Mongeon and Paul-Hus 2016) suggests that the largest indexing services currently are Elsevier's Scopus (with a bias towards researchers in Europe) and Clarivate's Web of Science (with a bias towards researchers in the US). While neither is a strict subset of the other, Scopus seems to have a slightly larger coverage $\left(22,800+\right.$ journals 4 as opposed to Web of Science's $\left.20,300+5^{5}\right)$. Based on this, Scopus was chosen as the primary resource for automated search.

To decide on a time period for the search, this survey relies on previously published supply chain risk literature reviews, where the earliest reviewed study is published in 1978. Hence, it is reasonable to set the time period from 1978 up to and including June 2018.

To assess and ensure completeness, three ancillary search procedures are included: (1) backwards snowballing (i.e. checking reference lists) on select primary studies; (2) title and abstract search on recent volumes of the most prominent journals in relevant fields and (3) comparison against the articles explored by previous literature reviews on supply chain risk (more details in Section 3.3).

\subsection{Search scope}

A series of inclusion and exclusion criteria frames the scope of this survey. First, studies must be peer-reviewed and written in English. Second, each study must include at least one practice, technique or methodology that has a proactive rather than a reactive approach to a risk-related issue in supply chains. Note that studies do not have to explicitly mention risk; instead, they may refer to uncertainty and/or any of the related notions in Section 2.2. Third, the aforementioned practice, technique or methodology must be artificially intelligent, according to the definition included in Section 2.5 .

Additional criteria focus on excluding studies that are not specifically related to supply chain, risk management and AI. Specifically, supply chain management publications with no concrete link to risk-related issues are excluded. Moreover, enterprise risk management publications with no clear connection to supply chain are also excluded. Studies are also excluded if the proposed approaches do not satisfy the AI definition in Section 2.5, e.g. if they rely exclusively on AHP, TOPSIS or FMEA methods. Finally, due to the Scopus limit of 2000 results per year, studies that have not been referenced at least once have also been excluded (this applies only to years 2013-2016).

\footnotetext{
${ }^{4}$ http://www.elsevier.com/solutions/scopus/content

${ }^{5}$ https://clarivate.libguides.com/webofscienceplatform/coverage
} 
Table 1.: Comparison with related surveys.

\begin{tabular}{|c|c|c|c|c|}
\hline Survey & Time period & $\begin{array}{l}\text { Reviewed } \\
\text { studies }\end{array}$ & $\begin{array}{l}\text { Shared } \\
\text { studies }\end{array}$ & Focus \\
\hline Behzadi et al. 2018, & $1993-2017$ & 42 & 5 & Agribusiness SCRM \\
\hline Ivanov et al. 2017 & 2001-2017 & 38 & 7 & SC disruption recovery \\
\hline (Govindan, Fattahı, and Keyvanshokooh 2017) & $2000-2015$ & 170 & 137 & $\begin{array}{l}\text { Supply chain network } \\
\text { design under uncertainty }\end{array}$ \\
\hline (Ho et al. 2015) & $2003-2013$ & 224 & 20 & SCRM in general \\
\hline (Ghadge, Danı, and Kalawsky 2012), & $2000-2010$ & 120 & 1 & $\begin{array}{l}\text { SCRM from a holistic } \\
\text { systems thinking perspective }\end{array}$ \\
\hline Colicchia and Strozzi 2012) & $1994-2010$ & 55 & 6 & SCRM in general \\
\hline Peidro et al. 2009) & $1988-2007$ & 103 & 27 & $\begin{array}{l}\text { Supply chain planning } \\
\text { under uncertainty }\end{array}$ \\
\hline (Vanany, Zailani, and Pujawan 2009) & $2000-2007$ & 82 & 2 & SCRM in general \\
\hline
\end{tabular}

A Scopus search as detailed in Section 3.1 yields more than 28,000 results. By carefully and thoroughly applying all aforementioned criteria and ancillary search strategies, 276 studies remain and are analysed in the rest of this paper ${ }^{6}$

\subsection{Related surveys}

Despite the relatively short history of SCRM as a distinct research field, several articles have been published with the aim of reviewing related literature. In Table 1, survey papers published in the past 10 years are summarised. Only surveys that present a detailed account of the search process and reference all reviewed studies are included, since their results can be replicated and compared. It should be noted that the only SCRM survey that uses the term AI to refer to a subset of applied methodologies is Peidro et al. (2009); however, it adopts a rather narrow view of AI, containing only multi-agent systems, reinforcement learning, evolutionary and genetic algorithms and fuzzy mathematical programming.

With the exception of Govindan, Fattahi, and Keyvanshokooh (2017), the number of shared studies with other surveys is low. This is either due to surveys being less recent (Vanany et al. (2009) and Peidro et al. (2009)), or due to adopting a more restricted focus: Ghadge, Dani, and Kalawsky (2012) and Colicchia and Strozzi (2012) focus mostly on strategic approaches to SCRM, Behzadi et al. (2018) include only agribusiness-related studies, and Ho et al. (2015) include only results that match both "supply chain" and risk.

Roughly $80 \%$ of the studies reviewed by Govindan, Fattahi, and Keyvanshokooh (2017) are also reviewed in this survey. This is due to the fact that quantitative approaches to supply chain network design under uncertainty most often involve some form of mathematical programming, which falls under the definition of AI in Section 2.5, since it is capable of autonomously making decisions (based on a mathematical optimisation model) under partially known (uncertain) environments. However, this survey includes a further 135 studies which have either been published after Govindan, Fattahi, and Keyvanshokooh (2017) or are not related to supply chain network design under uncertainty but are directly relevant to SCRM. Also, while their goal is to study the selected studies in terms of mathematical modelling, solution methods and optimisation techniques, the goal in this survey is to evaluate their AI-related capabilities, as well as their relevance to the typical phases in SCRM.

${ }^{6}$ The survey dataset can be provided in various formats (e.g. SciVal, EndNote, or .BIB/.RIS files) upon request to the corresponding author. 


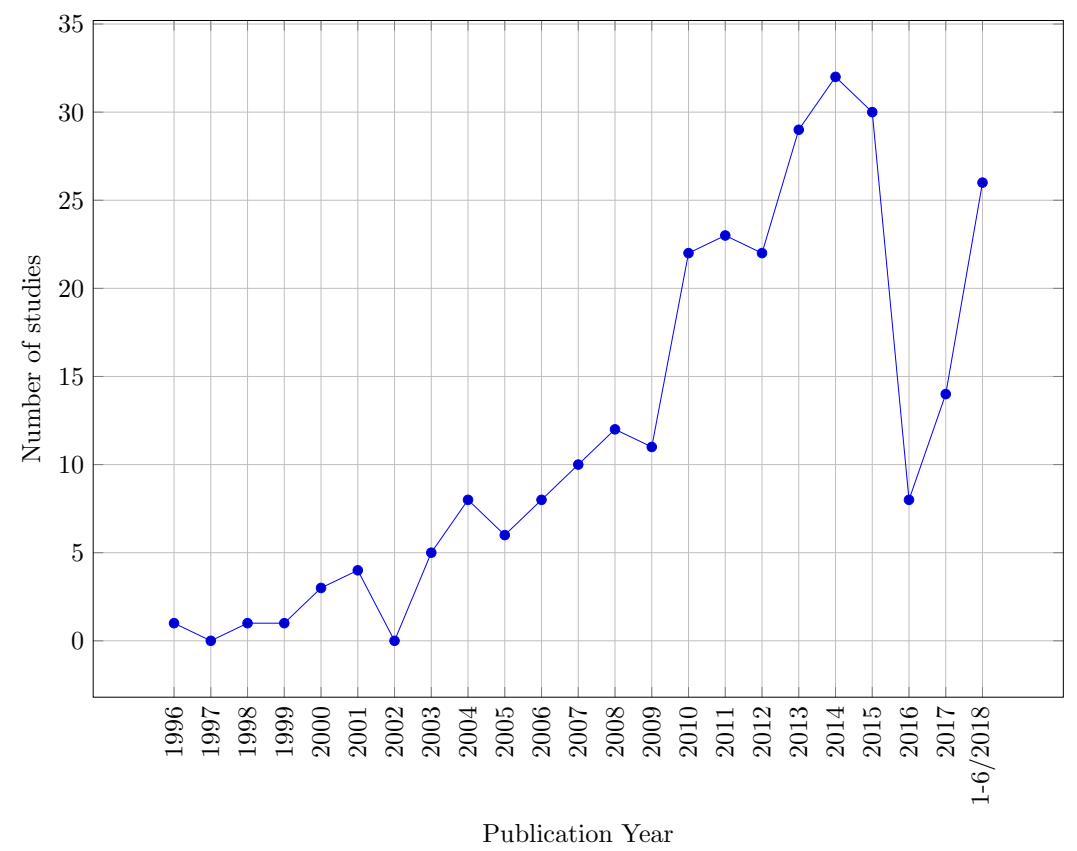

Figure 2.: Distribution of studies by publication year.

\section{Classification of reviewed studies}

In this section, the reviewed studies are classified according to the following characteristics: (1) year of publication, (2) venue (journal or conference) where the study is published and (6) the approach used to achieve SCRM-related goals.

\subsection{Year of publication}

As illustrated in Fig. 2, the trend of publishing AI-related research in SCRM confirms the results of previous surveys (e.g. (Fahimnia et al. 2015)), with a roughly geometric growth, from less than 5 studies before 2002, to more than 30 studies in 2014, fuelled by worldwide phenomena that have a direct or indirect effect on supply chains such as the post-2001 increase in terrorism, the 2008 global financial crisis and the post-2009 European debt crisis. There is a noticeable sharp drop in 2016 and a slight uptick in 2017. This can be attributed to a general decrease in the publication of SCRM studies and possibly a saturation in terms of the most popular quantitative approaches to SCRM which involve some form of stochastic or fuzzy programming. However, the trend seems to have completely reversed during 2018: we have identified 26 studies only during the first half of the year, which strongly suggests that the total for the whole year may surpass the 2014 peak. This renewed interest in AI-focused SCRM (and possibly SCRM in general) is likely linked to the recent AI resurgence and the uncertainty in global economy that is fuelled by the ongoing European debt crisis and global trade wars Hornby (2018). 


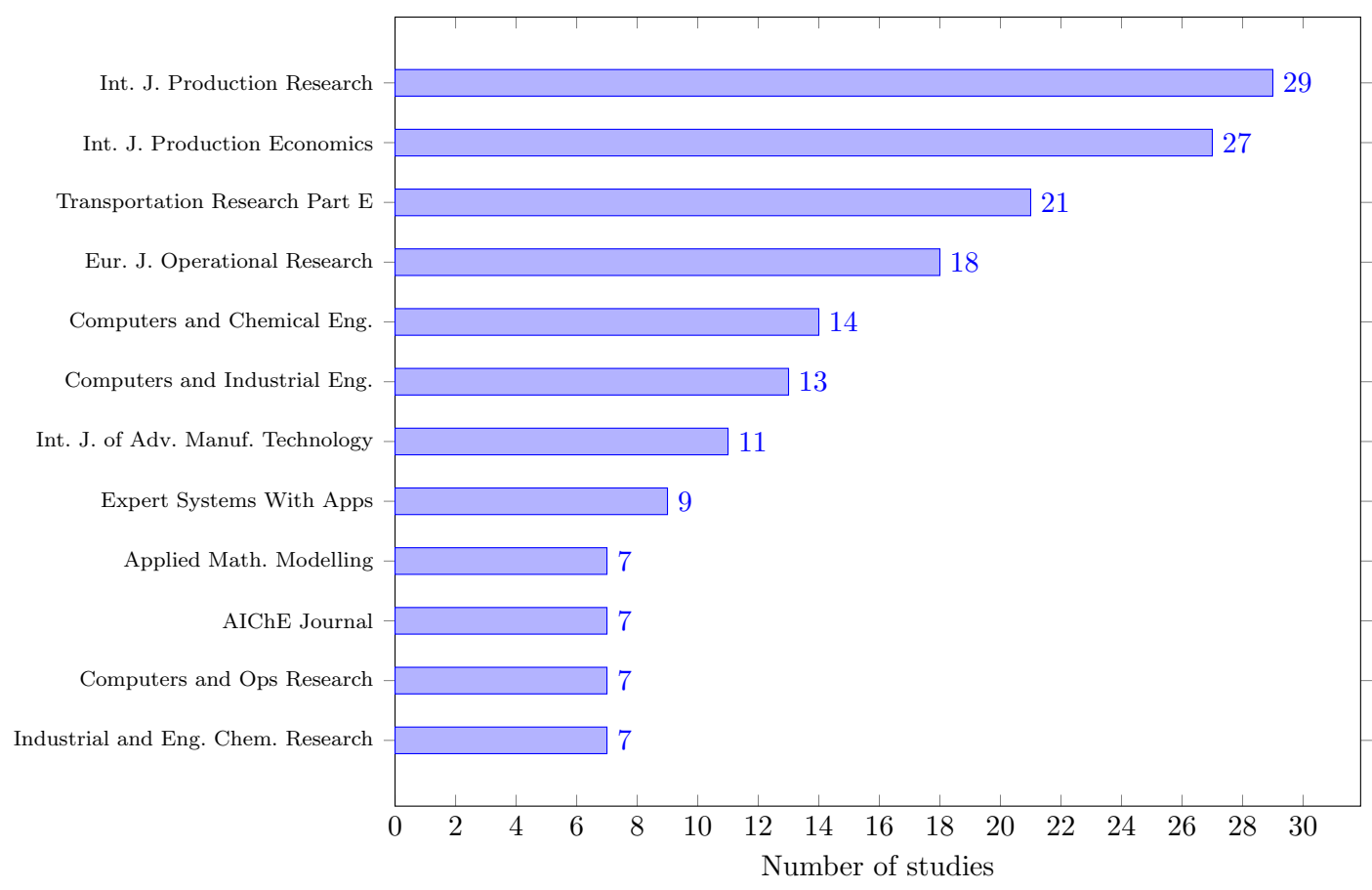

Figure 3.: Journals with the highest contribution in the conducted survey.

\subsection{Venue of publication}

Fig. 3 shows the top 10 journals ranked based on their contribution in the studies selected in this survey (note that there are 12 entries due to a three-way tie in tenth place). As should be expected, the most contributions come from production, logistics and operational research journals. Also, the list includes journals that involve computers, expert systems and engineering, due to this survey's focus on AI.

\subsection{Approach}

In terms of the approach adopted to tackle SCRM-related issues, the reviewed studies are classified in five categories, as shown in Fig. 4. The first category groups approaches that involve some form of mathematical programming and is divided into six subcategories. The most common case, representing $50 \%$ of the reviewed studies, is the use of stochastic programming to handle uncertainties, analysed in Section 5.1 . Other mathematical programming techniques include robust optimisation (Mulvey, Vanderbei, and Zenios 1995) and fuzzy programming (11\% and 19\% of the reviewed studies, respectively) and are discussed in Sections 5.2 and 5.3 . A few studies propose hybrid solutions that combine various forms of mathematical programming; these are examined in Section 5.4 .

The remaining four categories (representing 14\% of the reviewed studies) exploit various solutions proposed in AI research to achieve SCRM-related goals. These include network-based models such as Petri Nets and Bayesian networks (Section 5.5), multiagent systems (Section 5.6), automated reasoning (Section 5.7) and Machine Learning and Big Data Analytics (Section 5.8). 


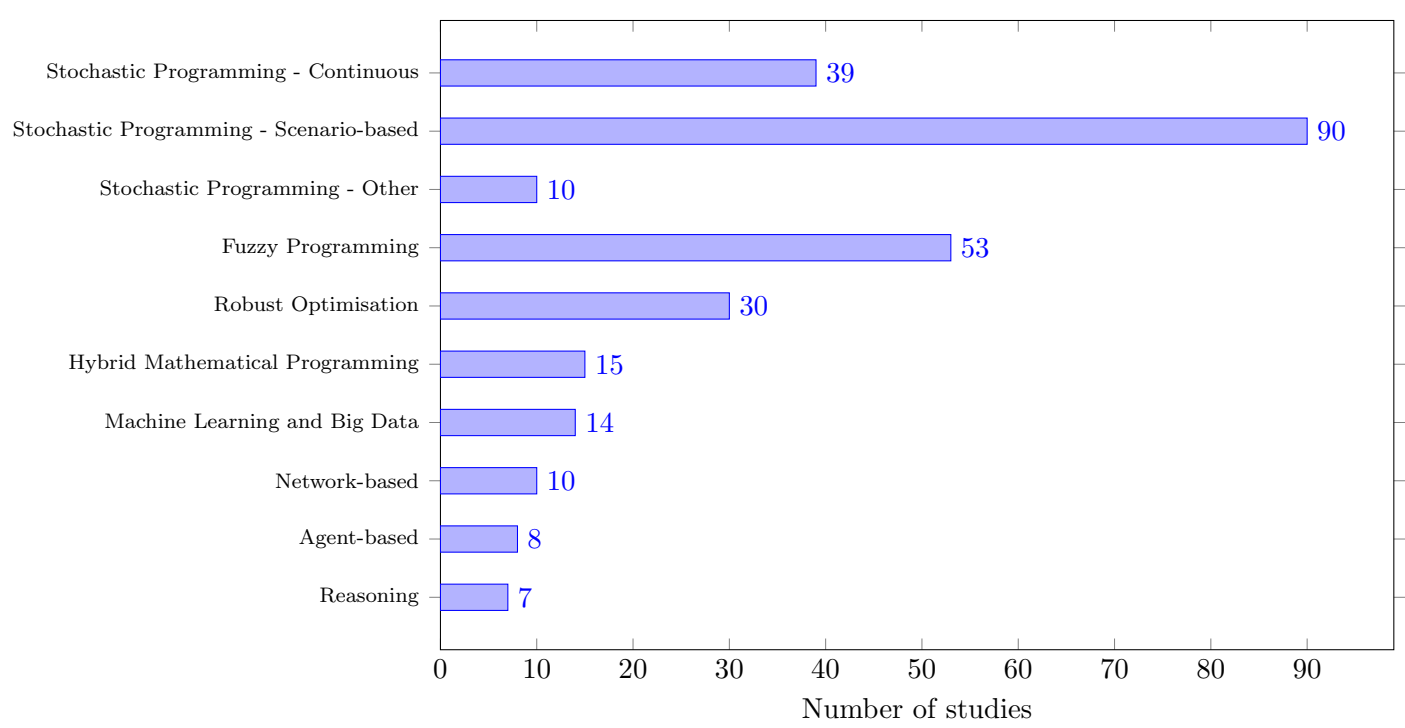

Figure 4.: Distribution of reviewed studies according to the adopted approach.

\section{AI-focused analysis of reviewed studies}

In this section, the selected studies are evaluated in terms of their AI-related capabilities: the number of risk/uncertain parameters considered, the exploitation of large datasets and their decision-making, predictive and learning capabilities. Results are presented in comparison tables, where a Yes/ /No value indicates full, limited or no support of the corresponding capability. Also, the SCRM tasks realised by each approach are determined, choosing among identification, assessment and response.

It should be noted that mathematical programming approaches (based on stochastic, fuzzy and robust optimisation models) fall under the umbrella of AI based on the definition in Section 2.5, due to their ability to assist in making decisions under partially unknown environments. However, such approaches exhibit limited decisionmaking capabilities, while their nature precludes any form of prediction or learning. As a compromise, this survey includes such studies, but they are only briefly discussed, though detailed comparison tables can be found in Appendix B.

\subsection{Stochastic Programming}

The most common approach to SCRM is to use stochastic parameters to model any aspect that is subject to risk or uncertainty and then optimise the resulting model with regard to one or more objective functions, often cost-related. The heart of any stochastic programming approach is the mathematical model which encodes the knowledge and expertise of the practitioners and researchers that propose it.

\subsubsection{Continuous parameters}

Some models rely on the assumption that continuous distributions for all uncertain parameters are known (or can be estimated) beforehand and all decisions are made based on these distributions. In most cases, a single uncertain parameter (most often demand) is included and evaluation is based on small-to-medium datasets, with the exception of You and Grossmann (2008), which presents a slightly larger case study 
of a US supply chain. All of the reviewed studies relate to risk response in the form of risk-aware or uncertainty-focused supply chain planning or design, while some of them (Dal-Mas et al. 2011; Azad and Davoudpour 2013; Azad et al. 2014) also provide risk evaluation by relying on risk measures such as CVaR.

In terms of decision making, research is mostly geared towards defining, solving and evaluating the proposed stochastic model, with less focus on how it may be integrated into an SCRM decision-making process. Some of the works (e.g. (Ryu, Dua, and Pistikopoulos 2004) or (Marufuzzaman et al. 2014)) do offer some managerial insights with regard to the obtained results without, however, incorporating these insights into a decision support system. Table B1 in Appendix B details all reviewed studies that incorporate stochastic programming with continuous parameters.

\subsubsection{Scenario-based}

Assuming a continuous distribution for uncertain parameters often leads to exceptionally complex problems that are hard to solve. Instead, parameter values can be assumed to be discrete (and finite), leading to a finite number of possible realisations, called scenarios, each one with an attached probability. This is usually combined with a two-stage setting, where some decisions are made beforehand, leading to a set of possible realisations; then, corrective actions (known as recourse) may need to be taken, in order to meet goals.

The scenario-based stochastic approach is by far the most popular modelling choice for SCRM. Its characterisation with regard to AI is similar to that of the previous subcategory; this should be expected as the approaches differ mainly in how values are attributed to uncertain parameters. The number of uncertain parameters is slightly increased in some studies (e.g. (You, Wassick, and Grossmann 2009; Schütz, Tomasgard, and Ahmed 2009; Ghavamifar, Makui, and Taleizadeh 2018)), though it should be noted that the more parameters a model incorporates, the less scenarios can be supported before the problem becomes exceedingly computationally complex. Tsiakis, Shah, and Pantelides (2001) is notable for using a Europe-wide supply chain network to evaluate the proposed model, while Koutsoukis et al. (2000) is one of the very few stochastic programming approaches that implements a prototype decision support system to assist the decision maker in addressing uncertain demand. All reviewed studies in this category are provided in Table B2 in Appendix B.

\subsubsection{Other}

Other SCRM-related approaches that involve stochastic optimisation primarily rely on chance-constrained (probabilistic) programming 7 (Gupta, Maranas, and McDonald 2000; Mitra et al. 2008; Guillén-Gosálbez and Grossmann |2010| Scott et al. 2015)) or dynamic programming (Huchzermeier and Cohen 1996 Fang et al.|2013). The former is used when there are "soft" constraints which need only be satisfied with a prespecified probability (or reliability level), while the latter applies a divide-and-conquer approach, by iteratively solving smaller sub-problems and reusing such solutions when possible.

Almost all studies in this category propose models that include a single uncertain parameter (related to demand or product quality) in order to design supply chains that are risk-aware, with the notable exception of Pasandideh, Niaki, and Asadi (2015),

${ }^{7}$ Note that probabilistic constraints are included in other studies as well, but as part of a hybrid approach, hence they are discussed in Section 5.4 
which includes 11 uncertain parameters and relies on genetic algorithms to find optimal solutions. None of the reviewed studies in this category support large datasets. In terms of decision-making capabilities, the work of Scott et al. (2015) stands out since it proposes a decision support system for order portfolio recommendation that combines chance-constrained optimisation with supplier selection using analytic hierarchy process. Table B3 in Appendix B offers a detailed comparison of the studies belonging to this category.

\subsection{Robust Optimisation}

If distributions for uncertain parameters are unavailable, robust optimisation techniques are a suitable alternative. In such techniques, uncertain parameters are assumed to have a finite set of possible realisations. Model solutions are evaluated in terms of solution-robustness and model-robustness. Solution-robustness determines how "close" to optimal a given solution is, measured using a cost function. Model-robustness evaluates how "feasible" the solution is, by examining which constraints are violated.

Robust optimisation approaches tend to focus on a limited number of parameters, usually 1 to 3 , mostly focusing on supply or demand uncertainties. In terms of exploiting large datasets, only two approaches consider this in a limited manner, in that they conduct evaluations with larger-than-average test sets: Pishvaee, Rabbani, and Torabi (2011) consider problems of size up to roughly 14 million elements while Dubey, Gunasekaran, and Childe (2015) include a scenario where the problem size rises up to $165 \times 10^{9}$.

Regarding decision-making capabilities, the only study that explicitly integrates the proposed robust optimisation model into a decision-making framework is that of Hahn and Kuhn (2012), although the decision-making process is still purely manual. Finally, all robust optimisation studies focus only on the risk response phase of SCRM. For a comparison of all studies based on robust optimisation, please refer to Table B4 in Appendix B.

\subsection{Fuzzy Programming}

In handling the inherent uncertainty of SCRM, it is sometimes useful to incorporate a level of flexibility in the assumed values of parameters or in the satisfaction of goals. This is realised through the use of fuzzy programming methods, where uncertain parameters are treated as fuzzy numbers and constraints as fuzzy sets. Note that, since the focus of this survey is on the risk aspects of supply chain, studies that rely solely on flexible programming have been excluded, since they assume uncertainty only on goals and not parameters.

While earlier approaches seem to support only a small number of fuzzy parameters, more recent studies have proposed models with more than 50 of them, as is the case of Pishvaee, Razmi, and Torabi (2014) and Babazadeh et al. (2017), with both reducing computational complexity by relying on techniques such as Benders decomposition or the $\epsilon$-constraint method. As should be expected, no approach directly supports large datasets, since model validation is almost always based on a limited case study.

In terms of decision making, there are three notable cases that propose decision support frameworks exploiting the defined fuzzy models. The latter three are analysed in more detail. Selim and Ozkarahan (2008) employ a simple feedback loop to modify coefficient values until an acceptable solution is reached. Tang, Lau, and Ho (2008) 
propose a two-phase knowledge framework for risk assessment, with experts formulating the initial input to genetic algorithms. Micheli, Mogre, and Perego (2014) propose a decision support system that involves the decision maker throughout the SCRM process, from the identification of risks and corresponding mitigation measures and budget to the definition of risk profiles in terms of likelihood and impact. It should also be noted that the work of Tang, Lau, and Ho (2008) is the only fuzzy programming study that focuses on risk assessment, rather than risk mitigation, as is the case for all others. Table B5 in Appendix B includes all reviewed studies that fall under the fuzzy programming category.

\subsection{Hybrid Approaches within Mathematical Programming}

A small subset of the SCRM approaches that exploit mathematical programming techniques do not belong strictly to one of the previous categories, either because they compare different techniques or because they attempt to combine two or more of them in a hybrid framework. Most cases involve employing fuzzy sets in relation to stochastic programming or robust optimisation. Two studies put different approaches head-tohead for the problem of supplier selection under risk but do not propose a full-fledged hybrid: Wu and Olson (2008) compare chance-constrained programming, data envelopment analysis and multi-objective programming, while Li and Zabinsky (2011) compare two-stage stochastic programming with chance-constrained programming models, noting that the latter requires less computational effort but does so at the penalty of discretising the relationships between parameters.

A hybrid approach combining chance-constrained and fuzzy models has been proposed by Pishvaee, Torabi, and Razmi (2012) for the design of a green supply chain under uncertainty. The proposed model includes constraints on fuzzy events (e.g. related to fuzzy demands) which do not need to always hold but which need to exceed a specific credibility threshold. Similar constraints are also used by Bai and Liu (2016) but within a robust optimisation setting. Vahdani et al. (2013) approach the design of a closed loop supply chain under uncertainty with a similar fuzzy chance-constrained hybrid, incorporating, however, interval programming as well. This allows their model to deal with uncertain parameters presented as intervals without knowing their distribution. Another fuzzy chance-constrained hybrid is proposed by Zhalechian et al. (2016) to simultaneously address the facility location and vehicle routing problems under uncertainty. Due to its complexity, a hybrid metaheuristic combining the self-adaptive genetic algorithm and variable-neighbourhood search is applied to solve it.

Instead of chance-constrained models, other proposals for supply chain network design under uncertainty combine fuzzy features with standard stochastic programming, such as the work of Felfel, Ayadi, and Masmoudi (2016), which uses a typical two-stage three-objective stochastic formulation; however, to select the preferred solution among Pareto-optimal alternatives, they maximise a fuzzy membership function that corresponds to a compromise among the three objectives. Vahdani et al. (2012) propose a similar hybrid for supply chain design under uncertain capacity and costs, but also calculate the robust counterpart of the model before solving it. Keyvanshokooh, Ryan, and Kabir (2016) propose a hybrid robust-stochastic programming approach due to their model incorporating stochastic uncertainty for transportation costs and polyhedral uncertainty sets for demand and return. Haddadsisakht and Ryan (2018) propose a similar robust-stochastic hybrid for closed-loop supply chain network design, but use stochastic uncertainty for demand and polyhedral uncertainty sets for carbon tax. 
Finally, Zahiri and Pishvaee (2017) propose a robust possibilistic model for supply chain network design with uncertain parameters following trapezoidal distributions and determining robustness based on the credibility measure.

Pavlov et al. (2018) address the problem of assessing the resilience of a supply chain using a hybrid methodology that combines fuzziness and the genome method. Supply chain reliability is modelled through possibility of failure, while the genome method is used to determine the most efficient structure for the supply chain network that achieves a certain (or maximum) reliability level. Jabbarzadeh, Fahimnia and Sabouhi (2018) use fuzzy c-means clustering to score supplier sustainability based on several criteria. These scores are then used as input parameters to a stochastic model that aims to minimise total cost and maximise sustainability performance, when the percentage of a supplier's capacity that is disrupted is uncertain.

Less common hybrids are centred around simulation techniques. Tong, Feng, and Rong (2012) present a two-stage scenario-based stochastic programming model for supply chain planning under fluctuating demand and yield and solve it using a simulation-based heuristic that can handle large scenario numbers. Claypool, Norman, and Needy (2014) model supply, demand and exposure risk within a mixed-integer programming model, whose solutions are used as inputs in a simulation that analyses the results of implementing them.

Regardless of the combination examined, the aforementioned studies exhibit a similar profile with regard to their AI-related features. Table B6 in Appendix B offers a comparison of hybrid mathematical programming approaches to SCRM. Most of them deal with a low number of uncertain parameters, with the exception of Vahdani et al. (2012) and Zhalechian et al. (2016), while none of them exploit large datasets. Almost all of them offer managerial insights on how the proposed models can assist in decision making but none propose a full-fledged decision support system. Finally, with the exception of Pavlov et al. (2018) which focuses on risk assessment, the rest focus on risk mitigation by addressing various issues in relation to supply chain network design under uncertainty.

\subsection{Network-based}

The complex and dynamic nature of SCRM decision making, especially under uncertainty, has led several researchers to adopt a network-based model to represent the various possible states, their outcomes and the possible transitions between them. Four studies have been identified that use some form of Petri Nets and five that use Bayesian Belief Network 8 , In addition, a Generalised Semi-Markov Process is used in a single study (Deleris, Elkins, and Paté-Cornell 2004) along with Monte Carlo simulation in order to estimate the probability distribution of supply chain losses caused by disruptions.

Reasoning Petri Nets are employed by Asar et al. (2006) to model supply chains as a discrete event system. The networks include rules that concern frequency and cause-effect relationships of events, as well as probability of threats. Using the networks, the authors are able to determine how threats propagate and what preventive actions are necessary. Supply chains have also been modelled using attributed Petri Nets (Rossi and Pero 2012), in order to be able to embed logistic parameters within the network. The authors compute the coverability graph of the network to identify

${ }^{8}$ Bayesian networks are only used in these studies only for inference. Studies that use such models for learning as well are classified within the Machine Learning and Big Data category, discussed in Section 5.8 
events that carry risk and assess that risk using simulation. Other variants include PTrans-Nets (Blackhurst, Wu, and O'Grady 2004), which employ probabilities and are used to simulate the performance of a supply chain, and Colored Petri Nets, used by Zegordi and Davarzani (2012) to model change propagation and calculate the impact of supply chain disruptions.

Bayesian networks have also been used for risk identification and assessment in literature. Badurdeen et al. (2014) use them to create a risk network map that captures the interrelations among risks and various driving factors; by inputting probabilities for these factors, the network is able to calculate probabilities for specific risks. The SCOR metrics model has also been mapped to a Bayesian network (Abolghasemi, Khodakarami, and Tehranifard 2015), in order to assess supply chain performance and evaluate potential affecting risks. Nepal and Yadav (2015) combine FMEA with Bayesian networks and decision trees for the particular case of supplier selection, computing probability and impact for sourcing risks, then calculating the total incurred cost per supplier in order to rank them.

Qazi et al. (2017) propose a holistic SCRM approach that uses FMEA to identify risks and risk sources, then employs Bayesian networks to build a risk dependency network and use it to determine risk propagation, rank risks based on appropriate measures and determine a fair allocation of budget to mitigation strategies. In a followup work (Qazi et al. 2018), the authors use fault tree analysis instead of FMEA and extend their approach to employ expected utility theory to capture different risk strategies and to include different decision criteria apart from cost.

Table 2.: Network-based approaches to SCRM.

\begin{tabular}{|c|c|c|c|c|c|c|c|c|}
\hline Reference & 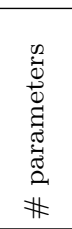 & 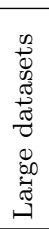 & 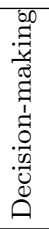 & 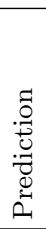 & 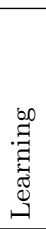 & 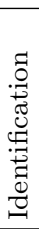 & 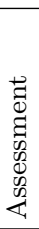 & 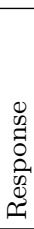 \\
\hline (Blackhurst, Wu, and O'Grady 2004$)$ & 7 & No & No & No & No & $\checkmark$ & $\checkmark$ & \\
\hline (Deleris, Elkıns, and Pate-Cornell 2004) & $\mathrm{N} / \mathrm{A}$ & No & No & No & No & & $\checkmark$ & \\
\hline Asar et al. 2006 & $\mathrm{N} / \mathrm{A}$ & No & No & No & No & $\checkmark$ & $\checkmark$ & \\
\hline (Rossi and Pero 2012$)$ & $\mathrm{N} / \mathrm{A}$ & No & No & No & No & $\checkmark$ & $\checkmark$ & \\
\hline (Zegordi and Davarzanı 2012) & $\mathrm{N} / \mathrm{A}$ & No & No & No & No & $\checkmark$ & $\checkmark$ & \\
\hline (Badurdeen et al. 2014) & $\mathrm{N} / \mathrm{A}$ & No & $\sim$ & No & No & $\checkmark$ & $\checkmark$ & \\
\hline (Abolghasemi, Khodakarami, and Tehranitard 2015 ) & $\mathrm{N} / \mathrm{A}$ & No & No & No & No & $\checkmark$ & $\checkmark$ & \\
\hline (INepal and Yadav 2015) & $\mathrm{N}^{\prime} / \mathrm{A}$ & No & $\sim$ & No & No & $\checkmark$ & $\checkmark$ & \\
\hline (Qazl et al. 2017) & $\mathrm{N} / \mathrm{A}$ & No & $\sim$ & No & No & $\checkmark$ & $\checkmark$ & $\checkmark$ \\
\hline Qazı et al. 2018) & $\mathrm{N}^{\prime} / \mathrm{A}$ & No & $\sim$ & No & No & $\checkmark$ & $\checkmark$ & $\checkmark$ \\
\hline
\end{tabular}

In contrast to the approaches discussed so far, network-based approaches rarely focus on a specific set of uncertain parameters or risks. Instead, they provide a generalised model that can be applied to model dynamic characteristics caused by uncertainty or risk. Hence, in most cases, the number of parameters is not relevant so it is marked as not applicable (N/A) in Table 2. No approaches utilise large datasets or support learning, while some of them offer limited decision-making support, by discussing how the proposed networks can be used by supply chain practitioners. Finally, all of the studies in this category provide for risk identification and risk assessment, instead of risk response which was the focus of almost all of the studies presented so far. 


\subsection{Agent-based}

SCRM is, by nature, a problem that involves several different entities interacting with each other, each with different and possibly conflicting requirements. Hence, it lends itself to agent-based formalisations, where entities within the supply chain are modelled as agents and SCRM-related issues are addressed by relying on multi-agent system research.

The earliest use of agents in the context of SCRM is the work of Kiekintveld et al. (2004), where an agent handles interactions with suppliers, customers, manufacturing and shipping operations, under circumstances of fluctuating supply and demand. The agent observes supply and demand conditions based on continuous market analysis and attempts to find a balance between them, which then has to be maintained by controlling all sales and procurements actions. Bansal et al.(2005) propose a similar agent-based approach that monitors key performance indicators (KPIs) to identify disruptions, then evaluates corrective actions and finds the optimal one. Note that these works are the first approaches in this survey so far to offer a holistic approach.

Multi-agent systems have also been used as simulation tools for inventory management to reduce costs and improve fill rate (Chan and Chan 2006), to resolve collaboration issues among supply chain entities that arise due to uncertain supply and demand (Kwon, Im, and Lee 2007) and to reduce costs and the bullwhip effect in a multi-stage supply chain (Zarandi, Pourakbar, and Turksen 2008). In all the aforementioned approaches, agent technology is preferred over mathematical optimisation due to its inherent capability to capture negotiation and coordination among different parties and the relatively less computational effort required. In contrast, Mele et al. (2007) propose a hybrid approach for retrofitting a production/distribution supply chain design to address uncertain demand, transport and processing times. A genetic algorithm is employed to solve a multi-stage stochastic model of the problem, but the fitness of each iteration's individuals is calculated using agent-based simulation.

The work of Giannakis and Louis (2011) is notable as it goes beyond simulation to explore the learning capabilities of multi-agent systems in the context of SCRM. The proposed framework addresses all SCRM phases and starts similarly to others by monitoring KPIs to identify deviations, which are then assessed in order to pinpoint the root cause. Through case-based learning, successful past decisions are leveraged when similarities with the current situation are identified (e.g. with regard to root causes). The optimal decision is selected and its results simulated and quantified, with all the information stored in order to be considered in similar situations in the future.

Recent work by Blos, da Silva and Wee (2018) proposes a holistic disruption management framework that combines multi-agent systems with variants of Petri Nets called Production Flow Systems and Place-Transition Petri Nets. The latter are used to model complex supply chain networks in several disruption scenarios. An agentbased system is used to generate more scenarios based on the existing ones, choose the most appropriate mitigation actions and evaluate the resulting effect in performance. Then, based on a risk event database, the supply chain is monitored in order to detect disruptions and immediately propose mitigation plans.

As shown in Table 3, the aforementioned agent-based approaches usually focus on very few parameters (up to 4), since it is difficult and computationally complex to simultaneously support a large number of policies that formalise agent behaviour. Similarly to previous categories, large datasets and predictive or learning capabilities are not supported, with the exceptions of the learning capability of Giannakis and Louis (2011) and the predictive capability of Blos, da Silva and Wee (2018). In 
Table 3.: Agent-based approaches to SCRM.

\begin{tabular}{|c|c|c|c|c|c|c|c|c|}
\hline Reference & 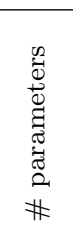 & 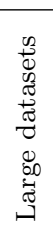 & 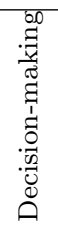 & 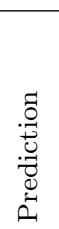 & 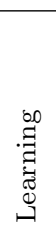 & 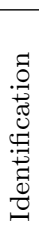 & 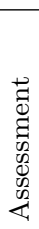 & 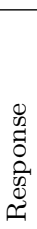 \\
\hline ( $\overline{\text { Kiekintveld et al. } 2004)}$ & 2 & No & Yes & No & No & $\checkmark$ & $\checkmark$ & $\checkmark$ \\
\hline (Bansal et al. 2005) & 1 & No & Yes & No & No & $\checkmark$ & $\checkmark$ & $\checkmark$ \\
\hline (Chan and Chan 2006) & 2 & No & $\sim$ & No & No & & & $\checkmark$ \\
\hline (Kwon, Im, and Lee 2007) & 4 & No & Yes & No & No & & & $\checkmark$ \\
\hline (Mile et al. 2007) & 4 & No & Yes & No & No & & & $\checkmark$ \\
\hline (Zarandi, Pourakbar, and Turksen 2008) & 2 & No & Yes & No & No & & & $\checkmark$ \\
\hline (Giannakis and Louis 2011) & $\mathrm{N} / \mathrm{A}$ & No & Yes & No & Yes & $\checkmark$ & $\checkmark$ & $\checkmark$ \\
\hline (Blos, da Silva, and Wee 2018) & $\mathrm{N} / \mathrm{A}$ & No & Yes & Yes & No & $\checkmark$ & $\checkmark$ & $\checkmark$ \\
\hline
\end{tabular}

stark contrast to previous categories, all but one of the agent-based approaches use multi-agent systems as a bona-fide decision support system for SCRM. This is probably because the very purpose of a multi-agent system is to solve problems through automated decision making.

\subsection{Reasoning}

Some researchers have addressed SCRM issues by exploiting automated reasoning techniques which rely on encoding expert knowledge in the form of rules or cases, making decisions based on these and the available data. These studies are summarised in Table 4 .

Table 4.: Reasoning-based approaches to SCRM.

\begin{tabular}{|c|c|c|c|c|c|c|c|c|}
\hline Reference & 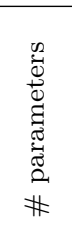 & 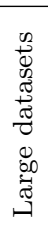 & 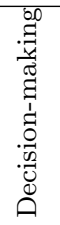 & 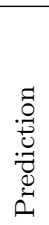 & 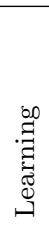 & 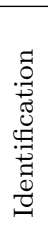 & 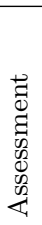 & $\begin{array}{l}0 \\
0 \\
0 \\
0 \\
0 \\
0 \\
0 \\
0 \\
0\end{array}$ \\
\hline (Kumar and Viswanadham 2007) & $\mathrm{N} / \mathrm{A}$ & No & Yes & No & No & $\checkmark$ & $\checkmark$ & $\checkmark$ \\
\hline (Behret, Oztayi, and Kahraman 2011) & 4 & No & $\sim$ & No & No & $\checkmark$ & $\checkmark$ & \\
\hline (Hofman 2011) & $\mathrm{N} / \mathrm{A}$ & Yes & $\sim$ & No & No & $\checkmark$ & $\checkmark$ & \\
\hline (Emmenegger, Laurenzi, and Thonssen 2012 ) & $\mathrm{N} / \mathrm{A}$ & Yes & Yes & No & No & $\checkmark$ & $\checkmark$ & \\
\hline Kayis and Karningsih 2012 & $\mathrm{N} / \mathrm{A}$ & No & No & No & No & $\checkmark$ & & \\
\hline Solank1 and Brewster 2013 & $\mathrm{N} / \mathrm{A}$ & Yes & No & No & No & $\checkmark$ & $\checkmark$ & \\
\hline (Paul 2015) & 18 & No & Yes & No & No & & & $\checkmark$ \\
\hline
\end{tabular}

Kumar and Viswanadham (Kumar and Viswanadham 2007) propose a decision support system for construction supply chains that relies on case-based reasoning. By using fault-tree analysis, important features of past projects that induce risk events are identified, categorised and stored. Then, for any future risk event, similar cases are retrieved and the corresponding solutions are adapted for the current case, which, in turn, gets stored to be reused in the future.

Behret, Öztayi, and Kahraman (2011) propose a fuzzy inference system that uses if-then rules to identify and assess potential risks, given risk indicator values. Triangular fuzzy numbers are used for all values, expressing low, medium or high levels of risk indicators and risks themselves. Paul (2015) proposes a similar approach for the particular case of supplier selection under risk, with rules associating selection factors with supplier rankings. Note that these are the only studies in this category that in- 
clude a specific number of parameters; in the rest, the reasoning process is assumed to apply to any type of risk.

Standard (i.e. not fuzzy) rules are employed in the works of Kayis and Karningsih (2012) and Emmenegger, Laurenzi, and Thönssen (2012). The former study encodes SCRM knowledge in the form of rule chains and uses them to identify risks as follows: specific characteristics of a supply network derive the occurrence of risk sub factors, sub factors derive risk factors, risk factors derive risk events and finally, the occurrence of a risk event leads to the system communicating this to the user. The latter study is notable as one of the few that aims to exploit large datasets collecting information from sources both within and beyond the supply chain in order to realise automatic identification, validation and quantification of risks.

Large datasets are also included in the studies of Hofman (2011) and Solanki and Brewster (2013) with the aim of increasing visibility in global supply chains. The authors argue that administrative burden can be decreased if supply chain participants share information such as product traceability as Linked Open Data, with appropriate privacy, security and access control mechanisms. By minimising the amount of data that is not visible, missing or uninterpretable, supply chain risk analysis may yield improved results.

\subsection{Machine Learning and Big Data}

Within the broad field of AI research, a rapid growth has been witnessed in recent years in relation to research that involves Machine Learning. This includes techniques that allow a computer program to learn by analysing input data, with or without being given information about the corresponding output (supervised and unsupervised forms). At the same time, the closely associated research strand of Big Data Analytics focuses on processing and extracting knowledge from datasets that are characterised by high volume, velocity and variety. As shown in Table 5, only a few SCRM studies have followed these recent AI developments.

Table 5.: Machine Learning and Big Data Analytics for SCRM.

\begin{tabular}{|c|c|c|c|c|c|c|c|c|}
\hline Reference & 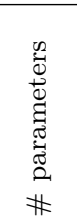 & 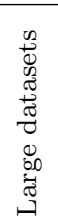 & 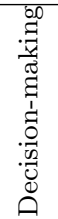 & 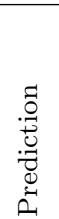 & 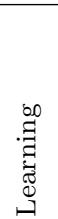 & 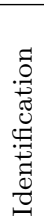 & 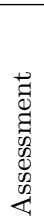 & 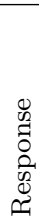 \\
\hline (Bruzzone and Orsoni 2003) & 2 & No & $\sim$ & Yes & Yes & & $\checkmark$ & \\
\hline (Jiang and Sheng 2009) & 1 & No & Yes & No & Yes & & & $\checkmark$ \\
\hline (Chen, Xia, and Wang 2010) & 1 & No & $\sim$ & Yes & Yes & & & $\checkmark$ \\
\hline (Zhao and Yu 2011$)$ & 7 & No & Yes & No & Yes & & & $\checkmark$ \\
\hline (Zage, Glass, and Colbaugh 2013) & $\mathrm{N} / \mathrm{A}$ & Yes & Yes & Yes & Yes & $\checkmark$ & & \\
\hline (Fan, Heilig, and Voss 2015$)$ & $\mathrm{N} / \mathrm{A}$ & Yes & Yes & No & Yes & $\checkmark$ & $\checkmark$ & $\checkmark$ \\
\hline (Garvey, Carnovale, and Yeniyurt 2015) & $\mathrm{N} / \mathrm{A}$ & No & $\sim$ & No & Yes & & $\checkmark$ & \\
\hline (He et al. 2015) & $\mathrm{N} / \mathrm{A}$ & Yes & Yes & Yes & Yes & $\checkmark$ & $\checkmark$ & $\checkmark$ \\
\hline (Ye, Xiao, and Zhu 2015 ) & $\mathrm{N} / \mathrm{A}$ & Yes & $\mathrm{No}$ & Yes & No & $\checkmark$ & & \\
\hline (Li and Wang 2017$)$ & 2 & Yes & $\sim$ & Yes & No & & & $\checkmark$ \\
\hline (IManı et al. 2017) & $\mathrm{N} / \mathrm{A}$ & Yes & $\sim$ & No & No & $\checkmark$ & & \\
\hline (Papadopoulos et al. 2017) & $\mathrm{N} / \mathrm{A}$ & Yes & $\sim$ & No & No & & & $\checkmark$ \\
\hline (Shang, Dunson, and song 2017) & 1 & Yes & Yes & Yes & No & & $\checkmark$ & \\
\hline (Ujha et al. 2018) & $\mathrm{N} / \mathrm{A}$ & No & $\sim$ & No & Yes & & $\checkmark$ & \\
\hline
\end{tabular}

The earliest SCRM study that involves some form of Machine Learning is Bruzzone and Orsoni (2003), which employs Artificial Neural Networks (ANNs) for risk assessment with regard to production losses. The ANNs are supplied with specific scenarios 
with production times, quantities and capacities (input), along with corresponding cost estimates (output). Based on these training data, the ANNs learn how to correlate input and output, gaining the capability of calculating cost estimates for different scenarios.

ANNs are also exploited in Zhao and $\mathrm{Yu}(2011)$ to solve the problem of supplier selection, while Jiang and Sheng (2009) propose a reinforcement learning algorithm to improve the supplier selection process. Chen, Xia, and Wang (2010) employ Bayesian learning to evaluate different responses to the problem of unreliable suppliers. Finally, Garvey, Carnovale, and Yeniyurt (2015) use Bayesian networks to model risk dependency graphs which have the ability to adapt when new knowledge is acquired, thus making sure that risk propagation is modelled accurately.

The most recent studies in this category use Big Data Analytics for various SCRM tasks. Generic SCRM frameworks based on Big Data are proposed in Fan, Heilig, and Voss (2015) and He et al. (2015), based on monitoring data both within and external to the supply chain. The case of fleet management is explored in Mani et al. (2017) with vehicle tracking systems employed to identify social and environmental risks (e.g. theft of vehicles and goods). On the other hand, Big Data are used in Papadopoulos et al. (2017) to determine how best to achieve supply chain resilience in the face of disaster. While the latter three studies do not use data sources for any predictive or learning purposes, there is a handful of recent studies that do and are briefly described next.

Zage, Glass, and Colbaugh (2013) analyse large amounts of Web data using semisupervised learning to determine the trustworthiness of vendors, thus allowing identification of deceivers. Risk identification is also explored by Ye, Xiao and Zhu (2015), focusing, however, on financial risk. Publicly available economic performance data for Chinese firms are collected are used to train multi-class Support Vector Machine (SVM) classifiers. These models are able to determine whether a firm is prone to supply, demand, product or external disruptions. Bayesian prediction is used in Shang, Dunson, and Song (2017) to assess transport time risks in air cargo supply chains. Li and Wang (2017) use big data collected by sensors in a food supply chain to dynamically predict the product time-temperature profile and adjust prices accordingly. Finally, Ojha et al. (2018) perform analysis of risk propagation using Bayes networks, automatically learning the interconnections between several risk factors for different supply chain stakeholders and using this knowledge to determine probability of occurrence and cost for risks.

\section{Discussion and Conclusions}

Based on the analysis in the previous section, answers to the research questions stated at the beginning of this survey are provided and a set of research gaps are identified with regard to applying AI technologies in SCRM. Then, for each one of the identified gaps, recommendations for future research are offered.

\subsection{Gaps}

While most of the reviewed studies focus on designing and evaluating a mathematical model that takes a number of uncertainties and risks into account, there is less focus on establishing and analysing the applicability of the proposed models. Indeed, as shown in Fig. 5a, 53\% of the reviewed studies do not provide any decision-making 


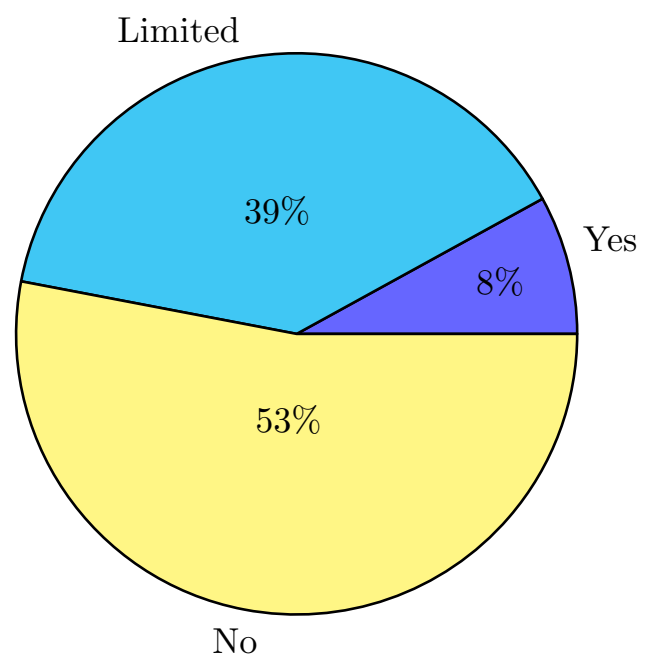

(a) Decision making

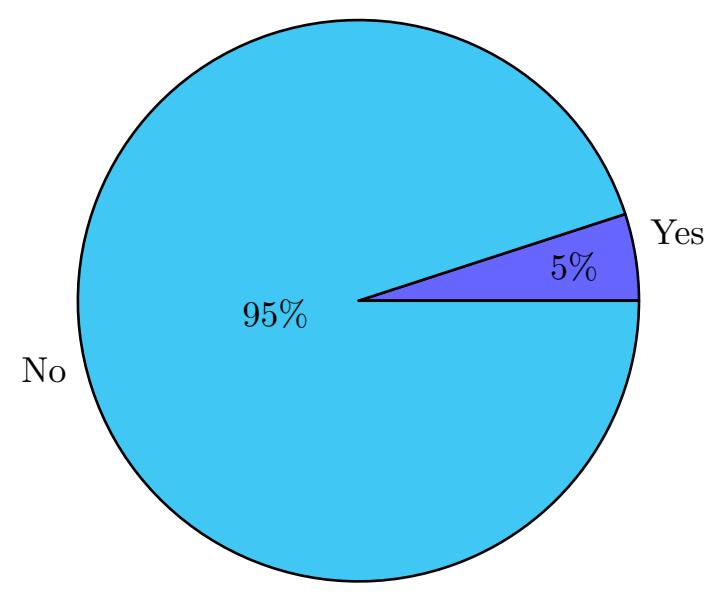

(b) Prediction and learning

Figure 5.: Decision-making, prediction and learning capabilities of reviewed studies.

capability whatsoever, while $39 \%$ offer some form of managerial insights to assist in decision making. Only $8 \%$ provide some form of decision support system, mainly in the agent-based, reasoning, Machine Learning and Big Data categories. Hence, the vast majority of studies exhibit a limited ability to act as a basis for a decision-making framework that can effectively support practitioners in managing supply chain risks. This hinders the potential benefits of the proposed models as it is difficult to answer "whether" and "how" they can be applied to relevant SCRM problems. Also, relatively little attention has been given to using the intelligence and knowledge gained from the proposed models to automate, at least partially, the decision-making process.

In terms of AI in the form of predictive and learning capabilities, SCRM research is still in its infancy, as illustrated in Fig. 5b. It is clear that, by definition, mathematical programming techniques do not have these capabilities. Although agent-based and network-based approaches are capable of prediction and learning, there is only one reported study (Giannakis and Louis 2011) that proposes a multi-agent system for SCRM that is capable of learning. On the other hand, Machine Learning approaches are, by definition, geared towards creating systems that can predict and learn based on provided input. However, initial studies (Bruzzone and Orsoni 2003; Jiang and Sheng 2009: Chen, Xia, and Wang 2010; Zhao and Yu 2011) have only explored few Machine Learning techniques, such as ANNs or Bayesian models. Newer techniques and recent advances in more established ones have yet to be exploited in the context of SCRM. The more recent studies of He et al. (2015) and Fan, Heilig, and Voss (2015) have provided conceptual SCRM frameworks that rely on Machine Learning techniques and Big Data but have not proceeded to implementing, applying and evaluating the frameworks. To the best of the authors' knowledge, the only recent studies that implement learning algorithms in the context of SCRM are Zage, Glass, and Colbaugh (2013), Garvey, Carnovale, and Yeniyurt (2015) and Ojha et al. (2018).

While the so-called Big Data and associated analysis techniques have made a considerable impact in various research fields and applications, this has not yet been made evident in the field of supply chain research, despite the potentially transformative capabilities of data science (Waller and Fawcett 2013, Choi, Wallace, and Wang 


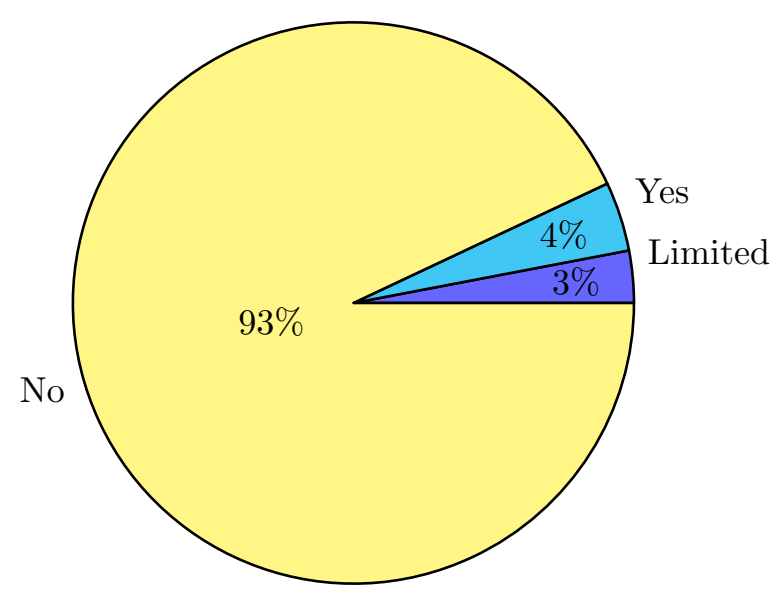

(a) Large datasets

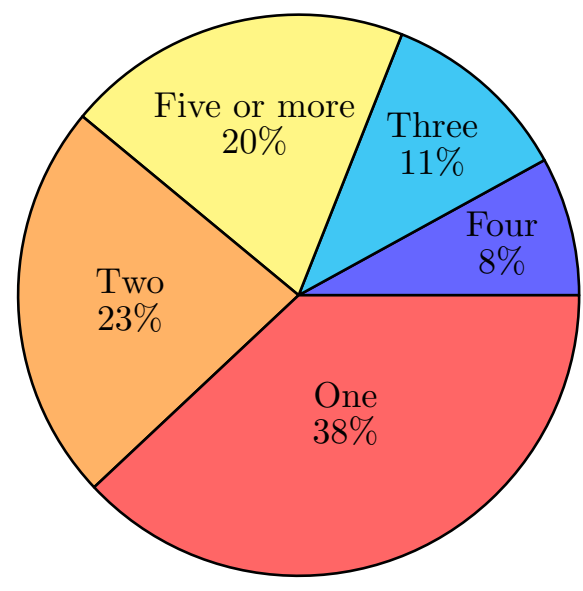

(b) Number of parameters

Figure 6.: Complexity of reviewed studies in terms of datasets and parameters.

2018). The results of this survey, illustrated in Fig. 6a. show that very few SCRM approaches exploit large datasets: $4 \%$ use Big Data aiming to improve supply chain visibility (Solanki and Brewster 2013), security (Zage, Glass, and Colbaugh 2013) and sustainability (Mani et al. 2017) and a further 3\% employ larger than average case studies, although in a Big Data scale. Much like the case of Machine Learning, SCRM research has yet to exploit the full potential of Big Data Analytics.

The complexity of the studies examined, with regard to the number of risk (or uncertainty) aspects taken into consideration, varies considerably from one category to another and even within categories. As shown in Fig. 6b, 38\% of those that explicitly state the employed models focus on a single uncertain parameter, $23 \%$ focus on two, $11 \%$ on three, $8 \%$ on four and the rest, $20 \%$ include models with 5 or more uncertain parameters. On average, it seems that using fuzzy programming techniques allows for the inclusion of a comparatively larger number of uncertain parameters. This is in line with the observation in literature that fuzzy models are, in general, easier to solve than stochastic ones and, hence, may accommodate more parameters in comparison(Inuiguchi and Ramík 2000).

Fig. 7 examines the reviewed studies with regard to the specific SCRM tasks they realise. The vast majority ( $84 \%$ ) focuses on risk response, most prominently supply chain models that avoid or mitigate risk and uncertainty effects. An additional $4 \%$ accompanies response with some form of risk assessment, while another $4 \%$ combines assessment with risk identification. Identification and assessment are tackled individually by very few studies ( $2 \%$ and $3 \%$, respectively). Finally, only 9 out of the 276 reviewed studies $(3 \%)$ offer holistic approaches, encompassing all three major phases of SCRM (identification, assessment and response). This imbalance parallels the difference in popularity among the employed techniques. Mathematical programming techniques have been applied by the majority of the examined studies and such techniques are suitable for risk response, sometimes augmented with assessment capabilities through the use of a variety of risk measures. Such techniques are not capable of identifying risks. This can only be achieved within the minority of studies that apply other solutions, from agents and network-based models, to automated reasoning, Machine Learning and Big Data Analytics. 


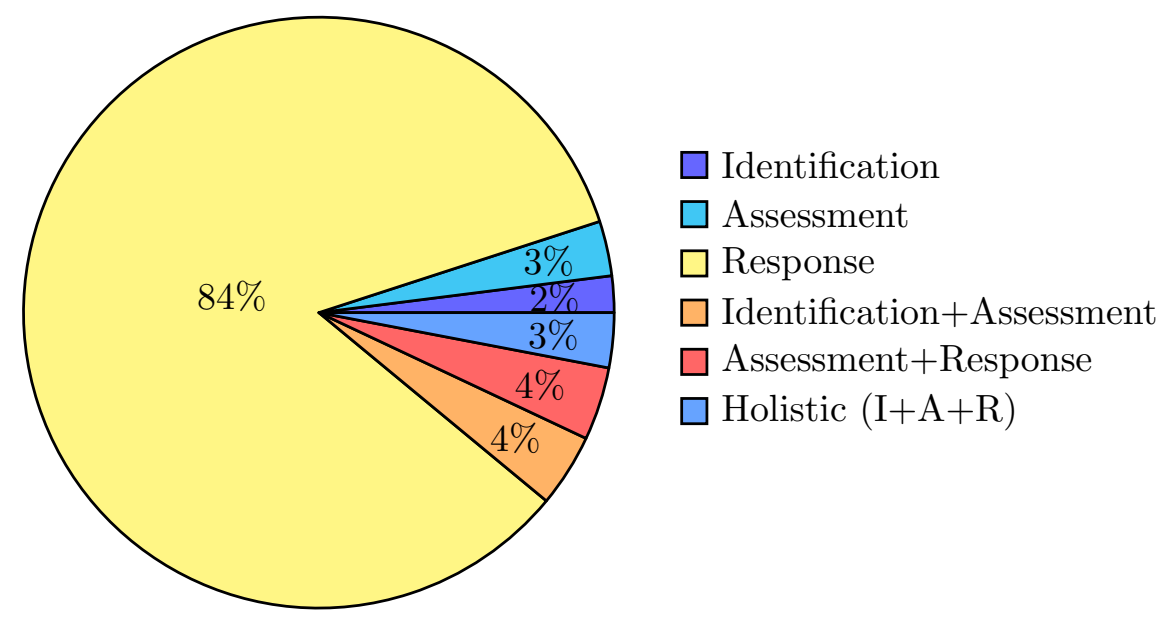

Figure 7.: SCRM tasks realised by the reviewed studies.

\section{2. $\quad$ Managerial insights}

The results of the survey indicate that supply chain and production researchers, in general, are more inclined to investigate tried and proven mathematical programming solutions rather than explore the potential of other AI techniques. This can be attributed to the relatively less exposure techniques such as machine learning, automated reasoning and multi-agent systems have had within production and supply chain research, despite the fact that they have been fruitful in other research areas. Additionally, researchers are considerably less familiar with such techniques than they are with stochastic or fuzzy programming, for instance.

A direct result of this imbalance is that decision makers in the industry are still widely unaware of the potential of AI, especially in terms of managing risks and uncertainty. However, this survey has uncovered the fact that relatively unexplored AI techniques are more capable of providing automated decision making, predictive and learning capabilities. Hence, decision makers should embrace these newer technologies and collaborate with researchers to determine ways in which SCRM decision-making can be improved. Note that this does not mean using AI as the sole decision maker, but rather relying on AI to uncover new knowledge that decision makers can then combine with their own expertise to arrive at the optimal decisions within the SCRM process.

A related aspect is the observed gradual shift from analytical models to data-driven ones, as evidenced in the work of Kuo and Kusiak (2018) for production research, in general. This, however, is directly dependent on the availability of large amounts of multi-dimensional data that should be as accurate as possible, since data-driven techniques can often result in trivial or even incorrect decisions if the available data is scarce or invalid. Thus, industry decision makers and stakeholders must strive to enhance and safeguard data collection processes and also be ready to provide any available data to SCRM researchers.

Availability of relevant data is often hindered by justifiable concerns related to data safety, security and transparency. Especially in the context of a supply chain, stakeholders may be unwilling to provide detailed data even to their supply chain partners. Fortunately, research in data security has led to several advances that guarantee pro- 
tected collection, storage and sharing of data. Blockchains are just one example of a promising technology that has the potential to increase trust among supply chain partners and increase adoption of techniques that rely on access to data (Mendling et al. 2018). Therefore, the concerns of supply chain decision makers and stakeholders should gradually be alleviated, removing data-related barriers to progress in terms of the adoption of AI technologies in SCRM.

\section{3. $\quad$ Future research directions}

The potential of modern AI techniques in realising proactive and predictive SCRM has only been explored by a minority of supply chain researchers. Hence, there are plenty of opportunities for research on the confluence of AI and SCRM that addresses the identified gaps. Some of these are outlined in the rest of this section.

\subsubsection{Decision making and applicability}

In terms of automating the decision-making process in relation to SCRM, there are several different alternatives that can be explored. Multi-agent systems, coupled with semantic reasoning on large datasets, can be used as a basis for a decision support system for SCRM, as explored in Giannakis and Louis (2016) for the purpose of increasing supply chain agility. To the extent that SCRM-related knowledge can be encoded in the form of rules, automated rule-based reasoning can be exploited, similarly to its use by Paul (2015) for supplier selection. The advantage, in this case, is that such a system can assist in various different SCRM tasks: rules can help in identifying risks, assessing their probability and impact and choosing a response strategy.

\subsubsection{Prediction and learning}

Machine learning techniques can also be employed to not only automate SCRM decisions but also transform traditional SCRM practices of of modelling supply chains statically to a dynamic representation of the supply chain adapted through learning and prediction. There are several different tasks within Machine Learning that can be exploited for SCRM. Indicatively, unsupervised learning algorithms can be employed to mine patterns in supply chain data that may be related to specific risks, assisting in risk identification. Alternatively, the algorithm can be trained to identify risk patterns based on example patterns that have been identified by practitioners. Learning-based classification and prediction can also facilitate the risk estimation, assessment and mitigation processes, as applied in other fields such as economics (Galindo and Tamayo $2000)$.

\subsubsection{Big Data}

In close correlation to Machine Learning, Big Data Analytics can also prove beneficial to SCRM, even if adoption is still relatively low. It is notable that, while research in other fields very often combines Machine Learning techniques with Big Data, the presented analysis only yielded a single SCRM study that features both of these characteristics, that of Zage, Glass, and Colbaugh (2013). This low adoption rate may be due to reasons such as lack of understanding and skills, inability to identify suitable data and low acceptance by SC partners (Nguyen et al. 2017).

As discussed by Waller and Fawcett (2013), data relevant to the supply chain can 
come from disparate sources, such as sales, consumer behaviour, product inventory, transportation and distribution. All of these sources, especially in the case of global supply chains, are characterised by large volumes, frequent updates and wide variability due to different materials, products and consumers. Several applications can be envisioned, from reducing demand uncertainty based on consumer behaviour, to using sensor data in distribution centres to mitigate transportation-related risks, to increasing visibility and trust among suppliers.

The untapped potential of Big Data Analytics and AI with regard to SCRM has also been identified by Ivanov and Dolgui (2018), who present a digitalisation framework that envisions a cyber supply chain sitting on top of traditional supply chain analytics. This cyber supply chain relies on and harnesses the power of big data, Internet of Things, cloud and blockchain technologies. The authors highlight the need for research that examines the relationships between these technologies and SCRM, a need that has also been made evident throughout this survey.

\subsubsection{Hybridisation}

Something evident throughout this survey is the fact that different AI techniques have a varying degree of applicability to the various phases of SCRM, due to possessing a different set of capabilities. For instance, mathematical programming approaches are successful in risk avoidance and mitigation but are incapable of automated decision making and learning or handling large amounts of data. These are achievable through automated reasoning, agents and Machine Learning techniques, which, however, are not so effective in modelling highly complex systems such as supply chains. Hence, it makes sense to investigate some form of hybridisation, which has previously only been attempted among different mathematical programming techniques. Research geared towards a hybrid framework that successfully combines powerful mathematical modelling and optimisation along with some other AI technique that is capable of automated decision making based on prediction and learning has the potential to achieve effective proactive and predictive management of risks in supply chains.

\section{References}

Abolghasemi, M., V. Khodakarami, and H. Tehranifard. 2015. "A new approach for supply chain risk management: Mapping SCOR into Bayesian network." Journal of Industrial Engineering and Management 8 (1): 280-302.

Asar, A., M.C. Zhou, R.J. Caudill, and S. Asar. 2006. "Modelling risks in supply chains using Petri net approach." International Journal of Services Operations and Informatics 1 (3): $273-285$.

Azad, N., and H. Davoudpour. 2013. "Designing a stochastic distribution network model under risk." International Journal of Advanced Manufacturing Technology 64 (1-4): 23-40.

Azad, N., H. Davoudpour, G.K.D. Saharidis, and M. Shiripour. 2014. "A new model to mitigating random disruption risks of facility and transportation in supply chain network design." International Journal of Advanced Manufacturing Technology 70 (9-12): 1757-1774.

Babazadeh, R., J. Razmi, M.S. Pishvaee, and M. Rabbani. 2017. "A sustainable secondgeneration biodiesel supply chain network design problem under risk." Omega 66: 258-277.

Badurdeen, F., M. Shuaib, K. Wijekoon, A. Brown, W. Faulkner, J. Amundson, I.S. Jawahir, T.J. Goldsby, D. Iyengar, and B. Boden. 2014. "Quantitative modeling and analysis of supply chain risks using Bayesian theory." Journal of Manufacturing Technology Management 25 (5): 631-654. 
Bai, X., and Y. Liu. 2016. "Robust optimization of supply chain network design in fuzzy decision system." Journal of Intelligent Manufacturing 27 (6): 1131-1149.

Bansal, M., A. Adhitya, R. Srinivasan, and I.A. Karimi. 2005. "An online decision support framework for managing abnormal supply chain events." Computer Aided Chemical Engineering $20(\mathrm{C}):$ 985-990.

Behret, H., B. Öztayi, and C. Kahraman. 2011. "A fuzzy inference system for supply chain risk management." Advances in Intelligent and Soft Computing 124: 429-438.

Behzadi, G., M.J. O'Sullivan, T.L. Olsen, and A. Zhang. 2018. "Agribusiness supply chain risk management: A review of quantitative decision models." Omega 79: 21-42.

Blackhurst, J., T. Wu, and P. O'Grady. 2004. "Network-based approach to modelling uncertainty in a supply chain." International Journal of Production Research 42 (8): 1639-1658.

Blos, Maurício Fontoura, Robson Marinho da Silva, and Hui-Ming Wee. 2018. "A framework for designing supply chain disruptions management considering productive systems and carrier viewpoints." International Journal of Production Research 0 (0): 1-17.

Bruzzone, A., and A. Orsoni. 2003. "AI and simulation-based techniques for the assessment of supply chain logistic performance." In Proceedings - Simulation Symposium, Vol. 2003January, 154-164.

Chan, F.T.S., and H.K. Chan. 2006. "A simulation study with quantity flexibility in a supply chain subjected to uncertainties." International Journal of Computer Integrated Manufacturing 19 (2): 148-160.

Chen, M., Y. Xia, and X. Wang. 2010. "Managing supply uncertainties through Bayesian information update." IEEE Transactions on Automation Science and Engineering 7 (1): 24-36.

Choi, T.-M., S. W. Wallace, and Y. Wang. 2018. "Big Data Analytics in Operations Management." Production and Operations Management .

Chopra, S., and M. S. Sodhi. 2014. "Reducing the Risk of Supply Chain Disruptions." MIT Sloan Management Review Spring (3): 73-80.

Claypool, E., B.A. Norman, and K.L. Needy. 2014. "Modeling risk in a Design for Supply Chain problem." Computers and Industrial Engineering 78: 44-54.

Colicchia, C., and F. Strozzi. 2012. "Supply chain risk management: A new methodology for a systematic literature review." Supply Chain Management 17 (4): 403-418.

Dal-Mas, M., S. Giarola, A. Zamboni, and F. Bezzo. 2011. "Strategic design and investment capacity planning of the ethanol supply chain under price uncertainty." Biomass and Bioenergy 35 (5): 2059-2071.

Deleris, L.A., D. Elkins, and M.E. Paté-Cornell. 2004. "Analyzing losses from hazard exposure: A conservative probabilistic estimate using supply chain risk simulation." In Proceedings Winter Simulation Conference, Vol. 2, 1384-1391.

Dubey, R., A. Gunasekaran, and S.J. Childe. 2015. "The design of a responsive sustainable supply chain network under uncertainty." International Journal of Advanced Manufacturing Technology 80 (1-4): 427-445.

Emmenegger, S., E. Laurenzi, and B. Thönssen. 2012. "Improving supply-chain-management based on semantically enriched risk descriptions." In KMIS 2012 - Proceedings of the International Conference on Knowledge Management and Information Sharing, 70-80.

Fahimnia, B., C.S. Tang, H. Davarzani, and J. Sarkis. 2015. "Quantitative models for managing supply chain risks: A review." European Journal of Operational Research 247 (1): 1-15.

Fan, Y., L. Heilig, and S. Voss. 2015. "Supply chain risk management in the era of big data." Lecture Notes in Computer Science 9186: 283-294.

Fang, J., L. Zhao, J.C. Fransoo, and T. Van Woensel. 2013. "Sourcing strategies in supply risk management: An approximate dynamic programming approach." Computers and Operations Research 40 (5): 1371-1382.

Felfel, H., O. Ayadi, and F. Masmoudi. 2016. "Multi-objective stochastic multi-site supply chain planning under demand uncertainty considering downside risk." Computers and Industrial Engineering 102: 268-279.

Galindo, J., and P. Tamayo. 2000. "Credit Risk Assessment Using Statistical and Machine 
Learning: Basic Methodology and Risk Modeling Applications." Computational Economics 15 (1): 107-143.

Garvey, M.D., S. Carnovale, and S. Yeniyurt. 2015. "An analytical framework for supply network risk propagation: A Bayesian network approach." European Journal of Operational Research 243 (2): 618-627.

Ghadge, A., S. Dani, and R. Kalawsky. 2012. "Supply chain risk management: Present and future scope." The International Journal of Logistics Management 23 (3): 313-339.

Ghavamifar, Ali, Ahmad Makui, and Ata Allah Taleizadeh. 2018. "Designing a resilient competitive supply chain network under disruption risks: A real-world application." Transportation Research Part E: Logistics and Transportation Review 115: 87 - 109.

Giannakis, M., and M. Louis. 2011. "A multi-agent based framework for supply chain risk management." Journal of Purchasing and Supply Management 17 (1): 23-31.

Giannakis, M., and M. Louis. 2016. "A multi-agent based system with big data processing for enhanced supply chain agility." Journal of Enterprise Information Management 29 (5): $706-727$.

Govindan, K., M. Fattahi, and E. Keyvanshokooh. 2017. "Supply chain network design under uncertainty: A comprehensive review and future research directions." European Journal of Operational Research 263 (1): 108-141.

Green, W. 2018. "Five lessons from the KFC chicken crisis." CIPS Supply Management .

Guillén-Gosálbez, G., and I. Grossmann. 2010. "A global optimization strategy for the environmentally conscious design of chemical supply chains under uncertainty in the damage assessment model." Computers and Chemical Engineering 34 (1): 42-58.

Gupta, A., C.D. Maranas, and C.M. McDonald. 2000. "Mid-term supply chain planning under demand uncertainty: Customer demand satisfaction and inventory management." Computers and Chemical Engineering 24 (12): 2613-2621.

Haddadsisakht, Ali, and Sarah M. Ryan. 2018. "Closed-loop supply chain network design with multiple transportation modes under stochastic demand and uncertain carbon tax." International Journal of Production Economics 195: 118 - 131.

Hahn, G.J., and H. Kuhn. 2012. "Value-based performance and risk management in supply chains: A robust optimization approach." International Journal of Production Economics 139 (1): 135-144.

He, M., H. Ji, Q. Wang, C. Ren, and R. Lougee. 2015. "Big data fueled process management of supply risks: Sensing, prediction, evaluation and mitigation." In Proceedings - Winter Simulation Conference, Vol. 2015-January, 1005-1013.

Heckmann, I., T. Comes, and S. Nickel. 2015. "A critical review on supply chain risk - Definition, measure and modeling." Omega 52: 119-132.

Ho, W., T. Zheng, H. Yildiz, and S. Talluri. 2015. "Supply chain risk management: A literature review." International Journal of Production Research 53 (16): 5031-5069.

Hofman, W. 2011. "Supply chain visibility with linked open data for supply chain risk analysis." In WITNESS 2011 - Proceedings of the 1st Workshop on IT Innovations Enabling Seamless and Secure Supply Chains, Vol. 769, 20-31.

Holton, G. 2004. "Defining Risk." Financial Analysts Journal 60 (6): 19-25.

Hornby, L. 2018. "US-China tariffs in charts: global supply chains at risk." Financial Times https://www.ft.com/content/bd99c39c-8024-11e8-bc55-50daf11b720d.

Huchzermeier, A., and M.A. Cohen. 1996. "Valuing operational flexibility under exchange rate risk." Operations Research 44 (1): 100-113.

Hudnurkar, Manoj, Sujeet Deshpande, Urvashi Rathod, and Suresh K. Jakhar. 2017. "Supply Chain Risk Classification Schemes: A Literature Review." Operations and Supply Chain Management: An International Journal 10 (4).

Inuiguchi, M., and J. Ramík. 2000. "Possibilistic linear programming: a brief review of fuzzy mathematical programming and a comparison with stochastic programming in portfolio selection problem." Fuzzy Sets and Systems 111 (1): 3-28.

Ivanov, Dmitry, Alexandre Dolgui, and Boris Sokolov. 2018. "The impact of digital technology and Industry 4.0 on the ripple effect and supply chain risk analytics." International Journal 
of Production Research 0 (0): 1-18.

Ivanov, Dmitry, Alexandre Dolgui, Boris Sokolov, and Marina Ivanova. 2017. "Literature review on disruption recovery in the supply chain." International Journal of Production Research 55 (20): 6158-6174.

Jabbarzadeh, Armin, Behnam Fahimnia, and Fatemeh Sabouhi. 2018. "Resilient and sustainable supply chain design: sustainability analysis under disruption risks." International Journal of Production Research 0 (0): 1-24.

Jiang, C., and Z. Sheng. 2009. "Case-based reinforcement learning for dynamic inventory control in a multi-agent supply-chain system." Expert Systems with Applications 36 (3 PART 2): $6520-6526$.

Jüttner, U. 2005. "Supply chain risk management: Understanding the business requirements from a practitioner perspective." The International Journal of Logistics Management 16 (1): 120-141.

Kayis, B., and P. D. Karningsih. 2012. "SCRIS: A knowledge-based system tool for assisting manufacturing organizations in identifying supply chain risks." Journal of Manufacturing Technology Management 23 (7): 834-852.

Keyvanshokooh, E., S.M. Ryan, and E. Kabir. 2016. "Hybrid robust and stochastic optimization for closed-loop supply chain network design using accelerated Benders decomposition." European Journal of Operational Research 249 (1): 76-92.

Khan, O., and B. Burnes. 2007. "Risk and supply chain management: Creating a research agenda." The International Journal of Logistics Management 18 (2): 197-216.

Kiekintveld, C., M.P. Wellman, S. Singh, J. Estelle, Y. Vorobeychik, V. Soni, and M. Rudary. 2004. "Distributed feedback control for decision making on Supply Chains." In ICAPS 2004 - Proceedings of the 14th International Conference on Automated Planning and Scheduling, 384-392.

Koutsoukis, N.-S., B. Dominguez-Ballesteros, C.A. Lucas, and G. Mitra. 2000. "A prototype decision support system for strategic planning under uncertainty." International Journal of Physical Distribution and Logistics Management 30 (7): 640-660.

Kumar, V., and N. Viswanadham. 2007. "A CBR-based decision support system framework for construction supply chain risk management." In CASE 2007 - Proceedings of the 3rd IEEE International Conference on Automation Science and Engineering, 980-985.

Kuo, Yong-Hong, and Andrew Kusiak. 2018. "From data to big data in production research: the past and future trends." International Journal of Production Research 0 (0): 1-26.

Kwon, O., G.P. Im, and K.C. Lee. 2007. "MACE-SCM: A multi-agent and case-based reasoning collaboration mechanism for supply chain management under supply and demand uncertainties." Expert Systems with Applications 33 (3): 690-705.

Legg, S., and M. Hutter. 2007. "Universal Intelligence: A Definition of Machine Intelligence." Minds and Machines 17 (4): 391-444.

Li, Dong, and Xiaojun Wang. 2017. "Dynamic supply chain decisions based on networked sensor data: an application in the chilled food retail chain." International Journal of Production Research 55 (17): 5127-5141.

Li, L., and Z.B. Zabinsky. 2011. "Incorporating uncertainty into a supplier selection problem." International Journal of Production Economics 134 (2): 344-356.

Lohr, S. 2016. "IBM Is Counting on Its Bet on Watson, and Paying Big Money for It." The New York Times https://www.nytimes.com/2016/10/17/technology/ ibm-is-counting-on-its-bet-on-watson-and-paying-big-money-for-it.html.

Lupton, D. 2013. Risk, 2nd ed., Chap. 2. Routledge.

Mani, V., C. Delgado, B.T. Hazen, and P. Patel. 2017. "Mitigating supply chain risk via sustainability using big data analytics: Evidence from the manufacturing supply chain." Sustainability 9 (4).

Manuj, I., and J.T. Mentzer. 2008a. "Global supply chain risk management." Journal of Business Logistics 29 (1): 133-155.

Manuj, I., and J.T. Mentzer. 2008b. "Global supply chain risk management strategies." International Journal of Physical Distribution and Logistics Management 38 (3): 192-223. 
March, J. G., and Z. Shapira. 1987. "Managerial Perspectives on Risk and Risk Taking." Management Science 33 (11): 1404-1418.

Martin, C., and H. Peck. 2004. "Building the Resilient Supply Chain." The International Journal of Logistics Management 15 (2): 1-14.

Marufuzzaman, M., S.D. Eksioglu, X. Li, and J. Wang. 2014. "Analyzing the impact of intermodal-related risk to the design and management of biofuel supply chain." Transportation Research Part E: Logistics and Transportation Review 69: 122-145.

Matthews, A. 2017. "Brexit Impacts on Irish Agri-food Exports to the UK." EuroChoices 16 (2): 26-32.

Mele, F.D., G. Guillén, A. Espuña, and L. Puigjaner. 2007. "An agent-based approach for supply chain retrofitting under uncertainty." Computers and Chemical Engineering 31 (56): $722-735$.

Mendling, J., I. Weber, W. M. P. van der Aalst, J. vom Brocke, C. Cabanillas, F. Daniel, S. Debois, et al. 2018. "Blockchains for Business Process Management - Challenges and Opportunities." ACM Trans. Management Inf. Syst. 9 (1): 4:1-4:16.

Micheli, G.J.L., R. Mogre, and A. Perego. 2014. "How to choose mitigation measures for supply chain risks." International Journal of Production Research 52 (1): 117-129.

Mitra, K., R.D. Gudi, S.C. Patwardhan, and G. Sardar. 2008. "Midterm supply chain planning under uncertainty: A multiobjective chance constrained programming framework." Industrial and Engineering Chemistry Research 47 (15): 5501-5511.

Mongeon, P., and A. Paul-Hus. 2016. "The journal coverage of Web of Science and Scopus: a comparative analysis." Scientometrics 106 (1): 213-228.

Mulvey, J. M., R. J. Vanderbei, and S. A. Zenios. 1995. "Robust Optimization of Large-Scale Systems." Operations Research 43 (2): 264-281.

Natarajarathinam, M., I. Capar, and A. Narayanan. 2009. "Managing supply chains in times of crisis: A review of literature and insights." International Journal of Physical Distribution and Logistics Management 39 (7): 535-573.

Nepal, B., and O.P. Yadav. 2015. "Bayesian belief network-based framework for sourcing risk analysis during supplier selection." International Journal of Production Research 53 (20): 6114-6135.

Nguyen, T., L. Zhou, V. Spiegler, P. Ieromonachou, and Y. Lin. 2017. "Big data analytics in supply chain management: A state-of-the-art literature review." Computers and Operations Research .

Norrman, A., and U. Jansson. 2004. "Ericsson's proactive supply chain risk management approach after a serious subsupplier accident." International Journal of Physical Distribution 8 Logistics Management 34 (5): 434-456.

Ojha, Ritesh, Abhijeet Ghadge, Manoj Kumar Tiwari, and Umit S. Bititci. 2018. "Bayesian network modelling for supply chain risk propagation." International Journal of Production Research 0 (0): 1-25.

Olhager, Jan. 2013. "Evolution of operations planning and control: from production to supply chains." International Journal of Production Research 51 (23-24): 6836-6843.

Papadopoulos, T., A. Gunasekaran, R. Dubey, N. Altay, S. J. Childe, and S. Fosso-Wamba. 2017. "The role of Big Data in explaining disaster resilience in supply chains for sustainability." Journal of Cleaner Production 142: 1108 - 1118.

Pasandideh, S.H.R., S.T.A. Niaki, and K. Asadi. 2015. "Bi-objective optimization of a multiproduct multi-period three-echelon supply chain problem under uncertain environments: NSGA-II and NRGA." Information Sciences 292: 57-74.

Paul, S.K. 2015. "Supplier selection for managing supply risks in supply chain: a fuzzy approach." International Journal of Advanced Manufacturing Technology 79 (1-4): 657-664.

Pavlov, A., D. Ivanov, A. Dolgui, and B. Sokolov. 2018. "Hybrid fuzzy-probabilistic approach to supply chain resilience assessment." IEEE Transactions on Engineering Management 65 (2): 303-315.

Peidro, D., J. Mula, R. Poler, and F.-C. Lario. 2009. "Quantitative models for supply chain planning under uncertainty." International Journal of Advanced Manufacturing Technology 
$43(3-4): 400-420$.

Pfohl, H.-C., H. Köhler, and D. Thomas. 2010. "State of the art in supply chain risk management research: Empirical and conceptual findings and a roadmap for the implementation in practice." Logistics Research 2 (1): 33-44.

Pishvaee, M.S., M. Rabbani, and S.A. Torabi. 2011. "A robust optimization approach to closedloop supply chain network design under uncertainty." Applied Mathematical Modelling 35 (2): 637-649.

Pishvaee, M.S., J. Razmi, and S.A. Torabi. 2014. "An accelerated Benders decomposition algorithm for sustainable supply chain network design under uncertainty: A case study of medical needle and syringe supply chain." Transportation Research Part E: Logistics and Transportation Review 67: 14-38.

Pishvaee, M.S., S.A. Torabi, and J. Razmi. 2012. "Credibility-based fuzzy mathematical programming model for green logistics design under uncertainty." Computers and Industrial Engineering 62 (2): 624-632.

Ponomarov, S. Y., and M. Holcomb. 2009. "Understaind the concept of supply chain resilience." The International Journal of Logistics Management 20 (1): 124-143.

Prakash, S., G. Soni, and A. P. S. Rathore. 2017. "A critical analysis of supply chain risk management content: a structured literature review." Journal of Advances in Management Research 14 (1): 69-90.

Qazi, A., J. Quigley, and A. Dickson. 2015. "Supply Chain Risk Management: Systematic literature review and a conceptual framework for capturing interdependencies between risks." In IEOM 2015 - Proceedings of the 5th International Conference on Industrial Engineering and Operations Management, 1-13.

Qazi, Abroon, Alex Dickson, John Quigley, and Barbara Gaudenzi. 2018. "Supply chain risk network management: A Bayesian belief network and expected utility based approach for managing supply chain risks." International Journal of Production Economics 196: 24 - 42.

Qazi, Abroon, John Quigley, Alex Dickson, and ule nsel Ekici. 2017. "Exploring dependency based probabilistic supply chain risk measures for prioritising interdependent risks and strategies." European Journal of Operational Research 259 (1): 189 - 204.

Rangel, Djalma Ara'ujo, Taiane Kamel de Oliveira, and Maria Silene Alexandre Leite. 2015. "Supply chain risk classification: discussion and proposal." International Journal of Production Research 53 (22): 6868-6887.

Rao, S., and T.J. Goldsby. 2009. "Supply chain risks: A review and typology." The International Journal of Logistics Management 20 (1): 97-123.

Rossi, T., and M. Pero. 2012. "A formal method for analysing and assessing operational risk in supply chains." International Journal of Operational Research 13 (1): 90-109.

Ryu, J.-H., V. Dua, and E.N. Pistikopoulos. 2004. "A bilevel programming framework for enterprise-wide process networks under uncertainty." Computers and Chemical Engineering 28 (6-7): 1121-1129.

Schlegel, G. L., and R. J. Trent. 2014. Supply Chain Risk Management: An Emerging Discipline, Chap. 1. CRC Press.

Schütz, P., A. Tomasgard, and S. Ahmed. 2009. "Supply chain design under uncertainty using sample average approximation and dual decomposition." European Journal of Operational Research 199 (2): 409-419.

Scott, J., W. Ho, P.K. Dey, and S. Talluri. 2015. "A decision support system for supplier selection and order allocation in stochastic, multi-stakeholder and multi-criteria environments." International Journal of Production Economics 166: 226-237.

Selim, H., and I. Ozkarahan. 2008. "A supply chain distribution network design model: An interactive fuzzy goal programming-based solution approach." International Journal of Advanced Manufacturing Technology 36 (3-4): 401-418.

Shang, Y., D. Dunson, and J.-S. Song. 2017. "Exploiting Big Data in Logistics Risk Assessment via Bayesian Nonparametrics." Operations Research 65 (6): 1574-1588.

Snyder, L.V., Z. Atan, P. Peng, Y. Rong, A.J. Schmitt, and B. Sinsoysal. 2016. "OR/MS models for supply chain disruptions: A review." IIE Transactions (Institute of Industrial 
Engineers) 48 (2): 89-109. Cited By 41.

Solanki, M., and C. Brewster. 2013. "Consuming linked data in supply chains: Enabling data visibility via linked pedigrees." In COLD 2013 - Proceedings of the Fourth International Conference on Consuming Linked Data, Vol. 1034, 74-86.

Solomonoff, R. J. 1985. "The time scale of artificial intelligence: Reflections on social effects." Human Systems Management 5 (2): 149-153.

Tang, C.S. 2006. "Perspectives in supply chain risk management." International Journal of Production Economics 103 (2): 451-488.

Tang, C.X.H., H.C.W. Lau, and G.T.S. Ho. 2008. "A conceptual fuzzy-genetic algorithm framework for assessing the potential risks in supply chain management." International Journal of Risk Assessment and Management 10 (3): 263-271.

Tang, O., and S. Nurmaya Musa. 2011. "Identifying risk issues and research advancements in supply chain risk management." International Journal of Production Economics 133 (1): $25-34$.

Tong, K., Y. Feng, and G. Rong. 2012. "Planning under demand and yield uncertainties in an oil supply chain." Industrial and Engineering Chemistry Research 51 (2): 814-834.

Tsiakis, P., N. Shah, and C.C. Pantelides. 2001. "Design of multi-echelon supply chain networks under demand uncertainty." Industrial and Engineering Chemistry Research 40 (16): 35853604 .

Vahdani, B., R. Tavakkoli-Moghaddam, F. Jolai, and A. Baboli. 2013. "Reliable design of a closed loop supply chain network under uncertainty: An interval fuzzy possibilistic chanceconstrained model." Engineering Optimization 45 (6): 745-765.

Vahdani, B., R. Tavakkoli-Moghaddam, M. Modarres, and A. Baboli. 2012. "Reliable design of a forward/reverse logistics network under uncertainty: A robust-M/M/c queuing model." Transportation Research Part E: Logistics and Transportation Review 48 (6): 1152-1168.

Vanany, I., S. Zailani, and N. Pujawan. 2009. "Supply chain risk management: Literature review and future research." International Journal of Information Systems and Supply Chain Management 2 (1): 16-33.

Vilko, J., P. Ritala, and J. Edelmann. 2014. "On uncertainty in supply chain risk management." International Journal of Logistics Management 25 (1): 3-19.

Waller, M. A., and S. E. Fawcett. 2013. "Data Science, Predictive Analytics, and Big Data: A Revolution That Will Transform Supply Chain Design and Management." Journal of Business Logistics 34 (2): 77-84.

World Economic Forum. 2012. New Models for Addressing Supply Chain and Transport Risk. Industry agenda. World Economic Forum.

Wu, D., and D.L. Olson. 2008. "Supply chain risk, simulation, and vendor selection." International Journal of Production Economics 114 (2): 646-655.

Ye, ShiJie, Zhi Xiao, and Guangfu Zhu. 2015. "Identification of supply chain disruptions with economic performance of firms using multi-category support vector machines." International Journal of Production Research 53 (10): 3086-3103.

You, F., and I.E. Grossmann. 2008. "Design of responsive supply chains under demand uncertainty." Computers and Chemical Engineering 32 (12): 3090-3111.

You, F., J.M. Wassick, and I.E. Grossmann. 2009. "Risk management for a global supply chain planning under uncertainty: Models and algorithms." AIChE Journal 55 (4): 931-946.

Zage, D., K. Glass, and R. Colbaugh. 2013. "Improving supply chain security using big data." 2013 IEEE International Conference on Intelligence and Security Informatics: Big Data, Emergent Threats, and Decision-Making in Security Informatics 254-259.

Zahiri, Behzad, and Mir Saman Pishvaee. 2017. "Blood supply chain network design considering blood group compatibility under uncertainty." International Journal of Production Research 55 (7): 2013-2033.

Zarandi, M.H.F., M. Pourakbar, and I.B. Turksen. 2008. "A Fuzzy agent-based model for reduction of bullwhip effect in supply chain systems." Expert Systems with Applications 34 (3): 1680-1691.

Zegordi, S.H., and H. Davarzani. 2012. "Developing a supply chain disruption analysis model: 
Application of colored Petri-nets." Expert Systems with Applications 39 (2): 2102-2111.

Zhalechian, M., R. Tavakkoli-Moghaddam, B. Zahiri, and M. Mohammadi. 2016. "Sustainable design of a closed-loop location-routing-inventory supply chain network under mixed uncertainty." Transportation Research Part E: Logistics and Transportation Review 89: 182-214.

Zhao, K., and X. Yu. 2011. "A case based reasoning approach on supplier selection in petroleum enterprises." Expert Systems with Applications 38 (6): 6839-6847.

Zhao, M., F. Javed, F. Jacob, and M. McNair. 2015. "SKILL: A system for skill identification and normalization." In IAAI 2015 - Proceedings of the 27th Conference on Innovative Applications of Artificial Intelligence, Vol. 5, 4012-4017. 


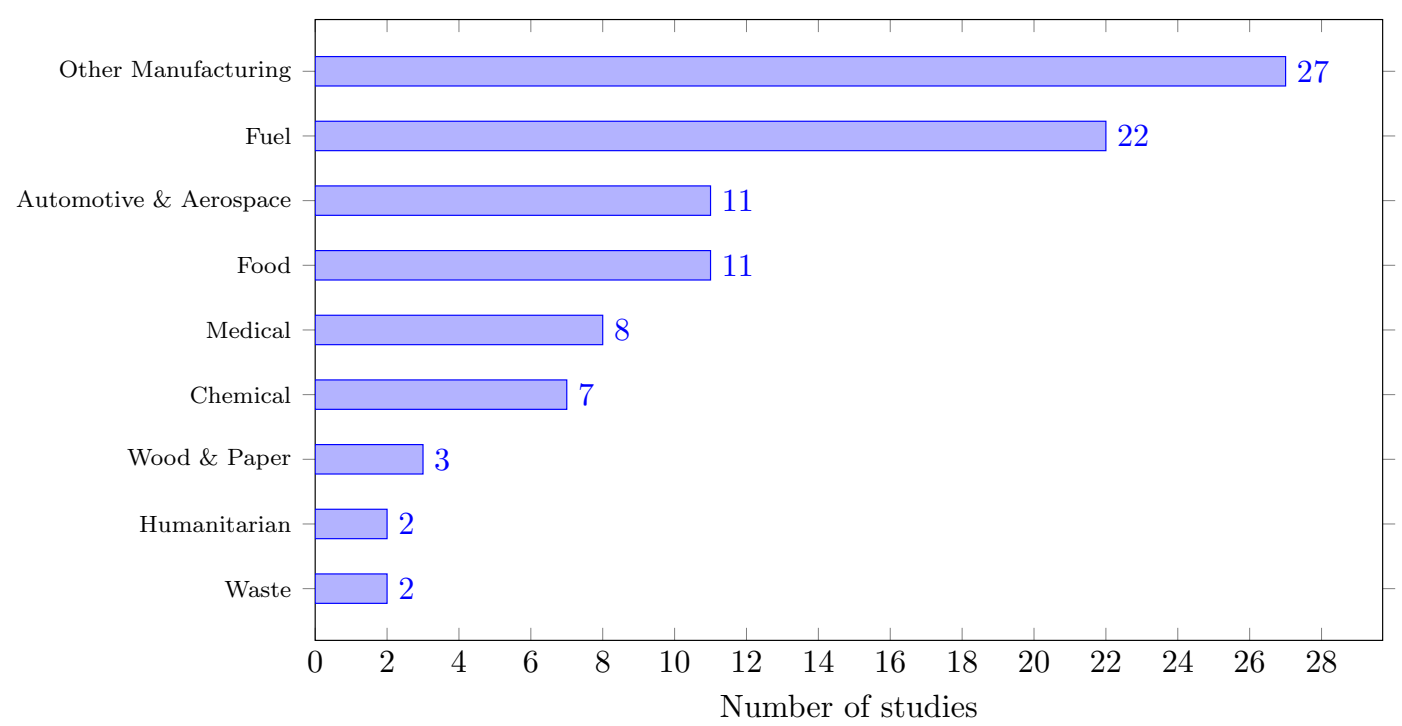

Figure A1.: Distribution of reviewed studies according to industrial case study presented.

\section{Appendix A. Additional classification metrics}

This appendix extends the classification presented in Section 4, to include three more metrics: (1) industry used as case study, (2) country used within case study and (3) risk or uncertainty types modelled.

\section{A.1. Case studies}

Fig. A1 shows the different industries that have been used as case studies in the reviewed literature. Note that only real-world case studies have been considered and not hypothetical supply chains or artificially generated numerical examples. The most common cases involve supply chains that manufacture and distribute various products, as well as supply chains that deal with fuel (from oil to biomass). The majority (66\%) of the reviewed studies does not include such a case study, a higher percentage than what has been reported in other surveys (e.g. Qazi, Quigley, and Dickson (2015) report $38 \%$ ). This is probably due to the quantitative nature of AI-related techniques: it is more likely to resort to randomly or otherwise generated test sets for such techniques, as opposed to qualitative and strategic approaches, which may also be informed by specific industries.

The countries related to the aforementioned case studies (if stated) are shown in Fig. A2, As should be expected, countries of case studies closely mirror the countries of the authors' affiliations.

\section{A.2. Risk and uncertainty types}

Most of the reviewed studies mention explicitly a set of parameters which they consider risky or uncertain and which they address through the proposed approach. The ratio of explicitly referencing uncertainty and risk is roughly $3: 1$, with 176 studies describing their research in relation to uncertainty and 66 studies relating it to risk. As mentioned 


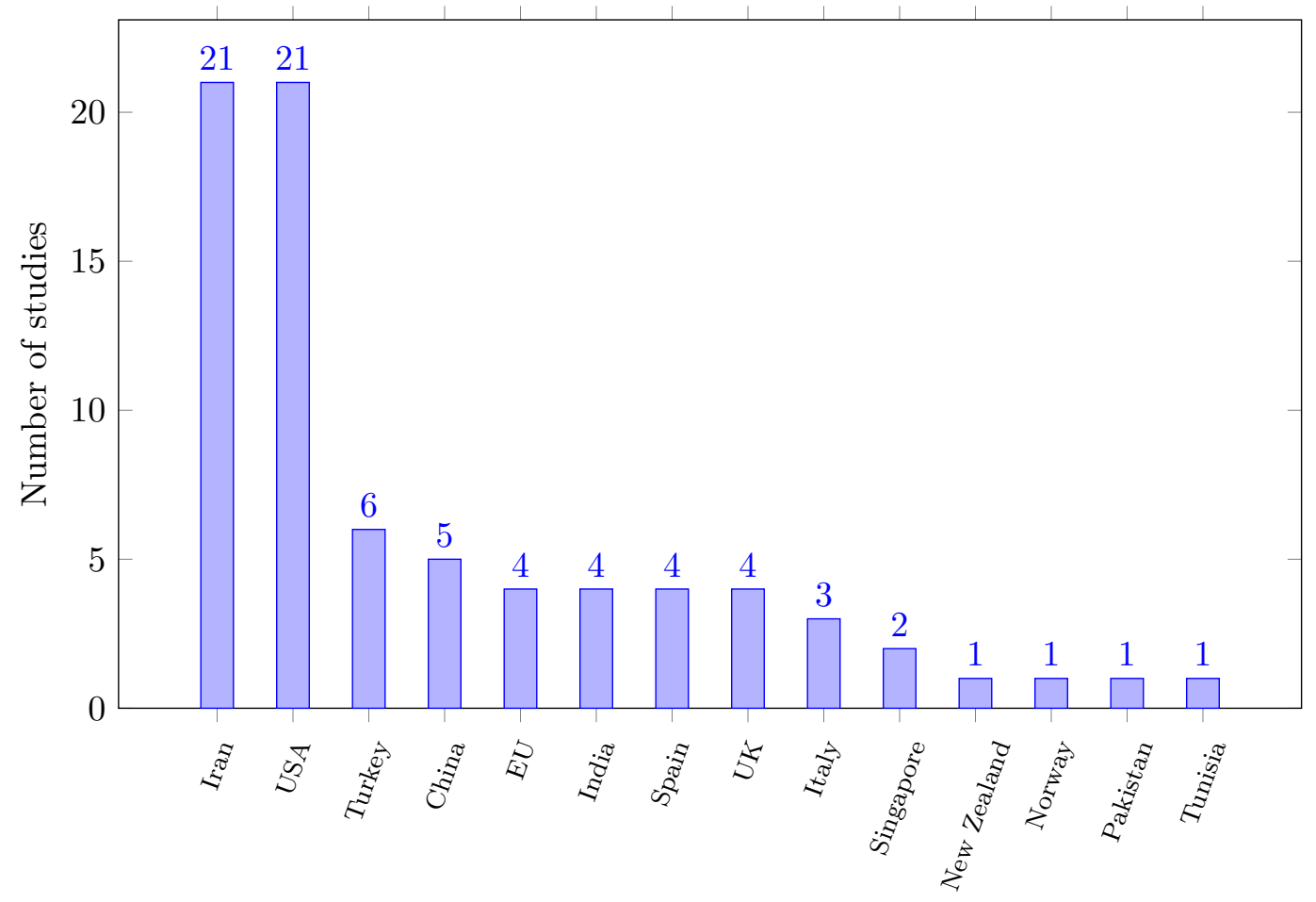

Figure A2.: Distribution of reviewed studies according to country of case study.

in Section 2.1, risk is most closely associated to disruptions or financial parameters, with other supply chain aspects more often linked to uncertainty.

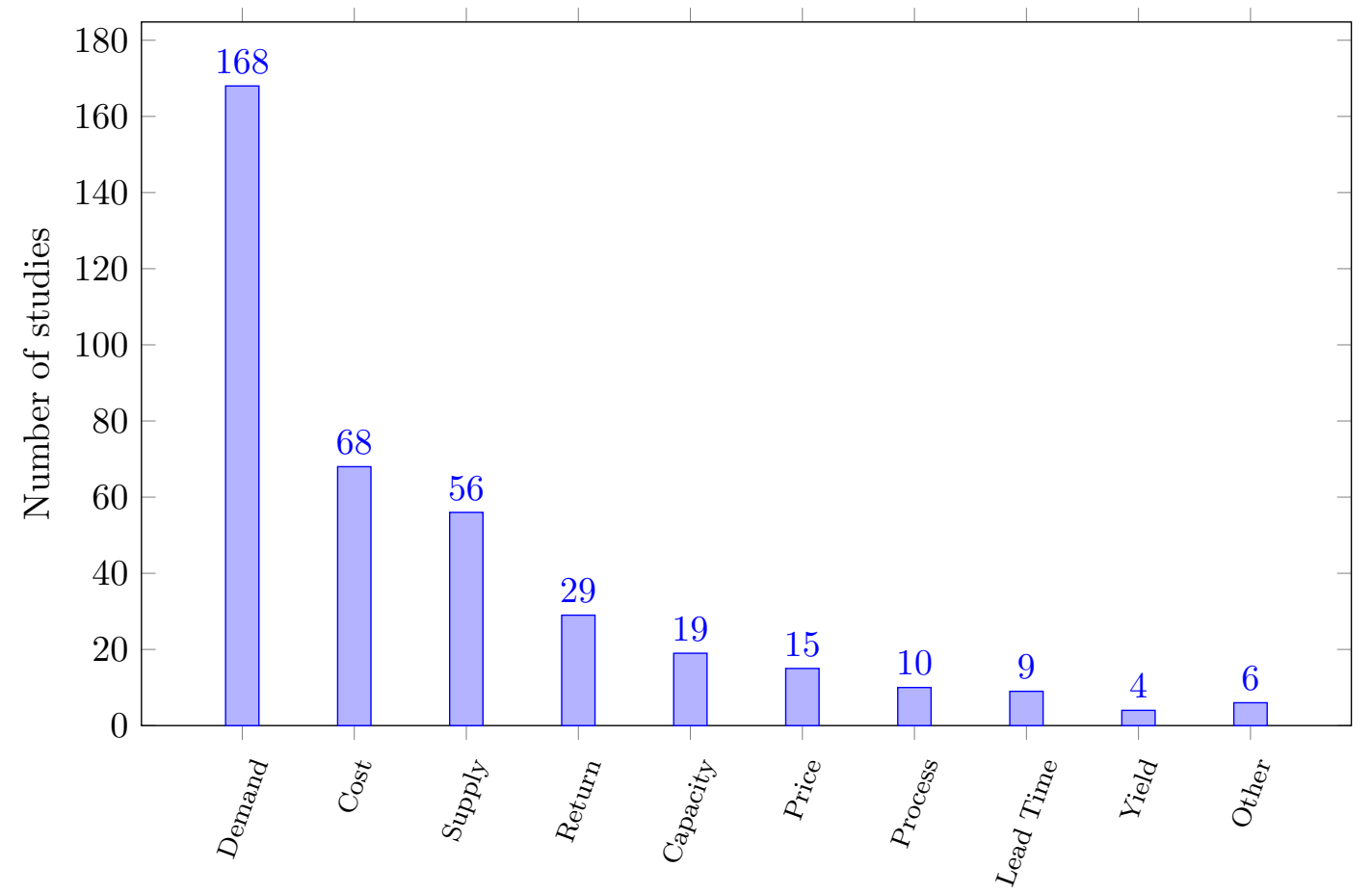

Figure A3.: Distribution of reviewed studies according to risk/uncertainty type. 
Fig. A3 shows the distribution of parameters associated with risk or uncertainty in the reviewed studies. The most common case, by far, is uncertain demand (or demand risk), followed by parameters related to cost and financial exposure. Supply risk (or uncertain supply) is also quite commonly tackled. Parameters such as return and capacity are primarily included in the case of reverse or closed-loop supply chains.

\section{Appendix B. Additional comparison tables}

In this appendix, detailed comparison tables are provided for the reviewed studies that involve some form of mathematical programming, which are briefly summarised in Sections 5.1, 5.2, 5.3 and 5.4 .

Table B1.: Stochastic programming approaches to SCRM with continuous parameters.

\begin{tabular}{|c|c|c|c|c|c|c|}
\hline Reference & 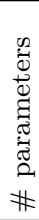 & 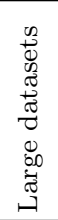 & 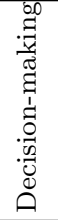 & 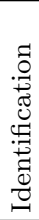 & 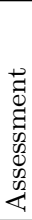 & 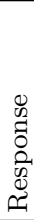 \\
\hline (Gupta and Maranas 2000) & 1 & No & No & & & $\checkmark$ \\
\hline (Guillèn et al. 2003) & 1 & No & No & & & $\checkmark$ \\
\hline (Lin and Chen 2003) & 1 & No & No & & & $\checkmark$ \\
\hline (Miranda and Garrıdo 2004) & 1 & No & No & & & $\checkmark$ \\
\hline (Ryu, Dua, and Pistikopoulos 2004) & 4 & No & $\sim$ & & & $\checkmark$ \\
\hline (Han and Damrongwongsirı 2005) & 1 & No & No & & & $\checkmark$ \\
\hline (Taplero and Grando 2006) & 2 & No & No & & & $\checkmark$ \\
\hline (Gaonkar and Viswanadham 2007) & 1 & No & No & & & $\checkmark$ \\
\hline (Lieckens and vandaele 2007) & 3 & No & No & & & $\checkmark$ \\
\hline (Q1 and Shen 2007) & 2 & No & No & & & $\checkmark$ \\
\hline Miranda and Garrido 2008) & 1 & No & No & & & $\checkmark$ \\
\hline ( You and Grossmann 2008 ) & 1 & $\sim$ & No & & & $\checkmark$ \\
\hline You and Grossmann 2008) & 1 & No & No & & & $\checkmark$ \\
\hline (Guillén-Gosálbez and Grossmann 2009) & 2 & No & No & & & $\checkmark$ \\
\hline (You and Grossmann 2009) & 1 & No & No & & & $\checkmark$ \\
\hline (Cul, Uuyang, and shen 2010) & 1 & No & No & & & $\checkmark$ \\
\hline (Hnaien, Delorme, and Dolgui 2010) & 1 & No & No & & & $\checkmark$ \\
\hline (Park, Lee, and sung 2010) & 1 & No & No & & & $\checkmark$ \\
\hline (Q1, Shen, and Snyder 2010) & 4 & No & No & & & $\checkmark$ \\
\hline (You and Grossmann 2010) & 1 & No & No & & & $\checkmark$ \\
\hline (Dal-Mias et al. 2011) & 2 & No & No & & $\checkmark$ & $\checkmark$ \\
\hline (Taleizadeh, Niaki, and Barzinpour 2011) & 1 & No & No & & & $\checkmark$ \\
\hline ( & 1 & No & No & & & $\checkmark$ \\
\hline (Liu, Shah, and Papageorgiou 2012 ) & 1 & No & No & & & $\checkmark$ \\
\hline (Azad and Davoudpour 2013) & 1 & No & $\sim$ & & $\checkmark$ & $\checkmark$ \\
\hline (Benyoucef, Xie, and Tanonkou 2013) & 1 & No & No & & & $\checkmark$ \\
\hline (Kumar and Tiwarı 2013) & 1 & No & No & & & $\checkmark$ \\
\hline ( & 1 & No & No & & & $\checkmark$ \\
\hline (Ȧzad et al. 2014) & 3 & No & No & & $\checkmark$ & $\checkmark$ \\
\hline (Jeong, Hong, and Xie 2014) & 2 & No & $\sim$ & & & $\checkmark$ \\
\hline (Marı, Lee, and Memon 2014) & 1 & No & $\sim$ & & & $\checkmark$ \\
\hline (Marutuzzaman et al. 2014) & 1 & No & No & & & $\checkmark$ \\
\hline (Nasiri, Zolfagharı, and Davoudpour 2014) & 1 & No & No & & & $\checkmark$ \\
\hline (Hnaien, Dolgui, and $\bar{w} \bar{u}$ zulb) & 2 & No & No & & & $\checkmark$ \\
\hline (Yongheng et al. 2014) & 1 & No & No & & & $\checkmark$ \\
\hline (Noorale and Parast 2015) & 1 & No & No & & & $\checkmark$ \\
\hline (Sharifzadeh, Garcia, and Shah 2015) & 2 & No & No & & & $\checkmark$ \\
\hline (Prasannavenkatesan and Goh 2016) & 1 & No & No & & & $\checkmark$ \\
\hline (Rayat, Musavı, and Bozorgl-Amiri 2017) & 1 & No & No & & & $\checkmark$ \\
\hline
\end{tabular}


Table B2.: Scenario-based stochastic programming approaches to SCRM.

\begin{tabular}{|c|c|c|c|c|c|c|}
\hline Reference & 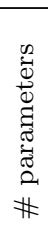 & 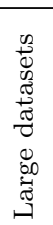 & 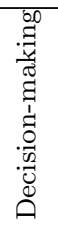 & 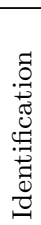 & 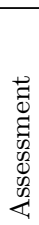 & $\begin{array}{c}0 \\
0 \\
0 \\
0 \\
0 \\
0 \\
\tilde{D}\end{array}$ \\
\hline Koutsoukis et al. 2000$)$ & 1 & No & Yes & & & $\checkmark$ \\
\hline (Chan, Carter, and Burnes 2001) & 1 & No & No & & & $\checkmark$ \\
\hline (Lucas et al. 2001) & 1 & No & No & & & $\checkmark$ \\
\hline (Tsiakis, Shah, and Pantelides 2001) & 1 & $\sim$ & No & & & $\checkmark$ \\
\hline (Alonso-Ayuso et al. 2003 & 3 & No & No & & & $\checkmark$ \\
\hline (Lababidi et al. 2004) & 2 & No & No & & & $\checkmark$ \\
\hline (Levis and Papageorgiou 2004 ) & 1 & No & No & & & $\checkmark$ \\
\hline (Guillèn et al. 2005) & 1 & No & No & & & $\checkmark$ \\
\hline (Santoso et al. 200b) & 4 & No & No & & & $\checkmark$ \\
\hline (Guillén, Espuña, and Puıglaner 2006) & 1 & No & No & & & $\checkmark$ \\
\hline (Guillen et al. 2006) & 1 & No & No & & & $\checkmark$ \\
\hline (Goh, Lim, and Meng 2007) & 2 & $\sim$ & No & & & $\checkmark$ \\
\hline (Lee et al. 2007) & 3 & No & No & & & $\checkmark$ \\
\hline (Salema, Barbosa-Povoa, and Novals 2007) & 2 & No & No & & & $\checkmark$ \\
\hline (Azaron et al. 2008) & 6 & No & No & & & $\checkmark$ \\
\hline (Bonfill, Espuña, and Puigianer 2008) & 3 & No & No & & & $\checkmark$ \\
\hline 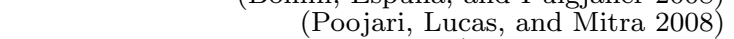 & 1 & No & No & & $\checkmark$ & $\checkmark$ \\
\hline (Lee and Dong 2009$)$ & 2 & No & No & & & $\checkmark$ \\
\hline (Schütz, Tomasgard, and Àmed 2009 ) & 11 & No & No & & & $\checkmark$ \\
\hline (Sodhl and Tang 200Y) & 1 & No & No & & & $\checkmark$ \\
\hline (You, Wassick, and Grossmann 2009) & 22 & No & No & & & $\checkmark$ \\
\hline (Franca et al. 2010) & 1 & No & $\sim$ & & & $\checkmark$ \\
\hline (Kara and Unut 2010) & 2 & No & $\sim$ & & & $\checkmark$ \\
\hline (Kumar, Tiwari, and Babiceanu 2010) & 3 & No & $\sim$ & & & $\checkmark$ \\
\hline (Lee, Dong, and Bian 2010) & 2 & No & No & & & $\checkmark$ \\
\hline (Sablo et al. 2010) & 2 & No & No & & & $\checkmark$ \\
\hline (Shu, Mla, and Li 2010) & 7 & No & No & & & $\checkmark$ \\
\hline (Cardona-Valdés, Álvarez, and Ozdemir 2011) & 1 & No & No & & & $\checkmark$ \\
\hline (Georgladis et al. 2011) & 1 & No & No & & & $\checkmark$ \\
\hline (Kim, Realtt, and Lee 2011) & 5 & No & No & & & $\checkmark$ \\
\hline (Longinıdıs and Georgiadıs 2011 ) & 1 & No & No & & & $\checkmark$ \\
\hline (Brdhandı and Yusutt 2011$)$ & 3 & No & No & & & $\checkmark$ \\
\hline (Rajgopal et al. 2011$)$ & 8 & No & No & & & $\checkmark$ \\
\hline (Sawik 2011) & 1 & No & No & & $\checkmark$ & $\checkmark$ \\
\hline (Shimizu, Fushimi, and Wada 2011 ) & 7 & No & No & & & $\checkmark$ \\
\hline (Shukla, Lalit, and Venkatasubramanian 2011) & 1 & No & No & & & $\checkmark$ \\
\hline (Almansoori and Shah 2012) & 1 & No & No & & & $\checkmark$ \\
\hline (Chen and Fan 2012) & 1 & No & No & & & $\checkmark$ \\
\hline (Gebreslassie, Yao, and You 2012 ) & 2 & No & No & & & $\checkmark$ \\
\hline (Giarola, Shah, and Bezzo 2012) & 2 & No & $\sim$ & & & $\checkmark$ \\
\hline (K1ya and Davoudpour 2012) & 2 & No & No & & & $\checkmark$ \\
\hline (Klibi and Martel 2012) & 2 & No & No & & & $\checkmark$ \\
\hline (IMak and shen 2012) & 2 & No & $\sim$ & & & $\checkmark$ \\
\hline (Nickel, Saldanha-da Gama, and Ziegler 2012$)$ & 2 & No & No & & & $\checkmark$ \\
\hline (Novan 2012$)$ & 4 & No & No & & & $\checkmark$ \\
\hline (PrasannaVenkatesan and Kumanan 2012) & 4 & No & No & & & $\checkmark$ \\
\hline (Ahmadi-Javid and Seddighi 2013) & 2 & No & No & & & $\checkmark$ \\
\hline (Aंmin and Zhang 2013) & 2 & No & No & & & $\checkmark$ \\
\hline (Awudu and Zhang 2013 & 2 & No & No & & & $\checkmark$ \\
\hline (Cardoso, Barbosa-Pvoa, and Relvas 2013) & 1 & No & No & & & $\checkmark$ \\
\hline (Kazemzadeh and $\overline{\mathrm{Hu}} 2013)$ & 2 & No & No & & & $\checkmark$ \\
\hline (Longinıdis and Georgiadıs 2013) & 7 & No & No & & & $\checkmark$ \\
\hline (Ulivelra et al. 2013 & 1 & No & No & & & $\checkmark$ \\
\hline (Pimentel, Mateus, and Almelda 2013) & 1 & No & No & & & $\checkmark$ \\
\hline (Q1n, Liu, and Tang 2013 & 1 & No & $\sim$ & & & $\checkmark$ \\
\hline (Ramezani, Bashiri, and Tavakkoll-Moghaddam 2013a) & 7 & No & No & & & $\checkmark$ \\
\hline (Ruiz-Femenia et al. 2013) & 1 & No & No & & & $\checkmark$ \\
\hline (Sawik 2013) & 1 & No & No & & $\checkmark$ & $\checkmark$ \\
\hline (Singh, Jain, and Mishra 2013) & 1 & No & No & & & $\checkmark$ \\
\hline (Cardona-Valdés, Álvarez, and Pacheco 2014) & 1 & No & No & & & $\checkmark$ \\
\hline (Dayhım, Jatarı, and Mazurek 2014) & 1 & No & No & & & $\checkmark$ \\
\hline (Ll and $\mathrm{Hu}$ 2014) & 3 & No & $\sim$ & & & $\checkmark$ \\
\hline (Liu and Guo 2014) & 6 & No & No & & & $\checkmark$ \\
\hline (Madadi et al. 2014a) & 2 & No & No & & & $\checkmark$ \\
\hline (Madadi et al. 2014b) & 2 & $\sim$ & $\sim$ & & $\checkmark$ & $\checkmark$ \\
\hline (Sawik 2014) & 1 & No & $\sim$ & & $\checkmark$ & $\checkmark$ \\
\hline (Soleimani and Govindan 2014) & 4 & No & No & & $\checkmark$ & $\checkmark$ \\
\hline (Soleimani, Seyyed-Esfahanı, and Kannan 2014) & 5 & No & No & & $\checkmark$ & $\checkmark$ \\
\hline (Zeballos et al. 2014) & 2 & No & $\sim$ & & & $\checkmark$ \\
\hline \multicolumn{7}{|c|}{ Continued on next page } \\
\hline
\end{tabular}


Table B2.: (continued)

\begin{tabular}{|c|c|c|c|c|c|c|}
\hline Reference & 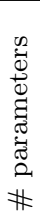 & 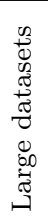 & 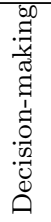 & 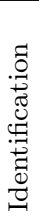 & $\begin{array}{l}\text { E्च } \\
\text { ¿्य } \\
0 \\
0 \\
0 \\
0 \\
0 \\
0\end{array}$ & 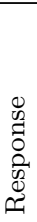 \\
\hline (Ayvaz, Bolat, and Aydin $\overline{2015})$ & 2 & No & No & & & $\sqrt{ }$ \\
\hline (Fattahı et al. 2015) & 1 & No & No & & & $\checkmark$ \\
\hline (Govindan, Jafarian, and Nourbakhsh 2015 ) & 1 & No & No & & & $\checkmark$ \\
\hline (Khatamı, Mahootchi, and Farahanı 2015 ) & 2 & No & No & & & $\checkmark$ \\
\hline (Kilic and Tuzkaya 2015) & 3 & No & No & & & $\checkmark$ \\
\hline (Sawik 2015) & 1 & No & No & & & $\checkmark$ \\
\hline (Sawik 2016) & 1 & No & $\sim$ & & & $\checkmark$ \\
\hline (Behzadi et al. 2017) & 1 & No & $\sim$ & & & $\checkmark$ \\
\hline (Chatzikontidou et al. 2017) & 1 & No & No & & & $\checkmark$ \\
\hline (Kamalahmadı and Parast 2017) & 1 & No & $\sim$ & & & $\checkmark$ \\
\hline (Ghavamifar, Makuı, and Taleızadeh 2018) & 9 & No & $\sim$ & & & $\checkmark$ \\
\hline (Jalalı, Seltbarghy, and Nıakı 2018) & 2 & No & $\sim$ & & & $\checkmark$ \\
\hline (Jerbia et al. 2018) & 6 & No & No & & & $\checkmark$ \\
\hline (Namdar et al. 2018) & 4 & No & $\sim$ & & & $\checkmark$ \\
\hline (Parıazar and Sir 2018) & 3 & No & $\sim$ & & & $\checkmark$ \\
\hline (Rahimi and Ghezavati 2018) & 3 & No & $\sim$ & & & $\checkmark$ \\
\hline (Sawik 2018) & 2 & No & $\sim$ & & & $\checkmark$ \\
\hline (Song, Chen, and Lei 2018) & 2 & No & $\sim$ & & & $\checkmark$ \\
\hline (Weskamp et al. 2018) & 1 & No & $\sim$ & & & $\checkmark$ \\
\hline (Xie and Huang 2018) & 1 & No & $\sim$ & & & $\checkmark$ \\
\hline (Zahirı et al. 2018) & 2 & No & $\sim$ & & & $\checkmark$ \\
\hline
\end{tabular}

Table B3.: Other stochastic programming approaches to SCRM

\begin{tabular}{|c|c|c|c|c|c|c|}
\hline Ref & 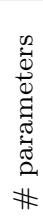 & 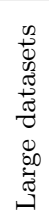 & 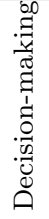 & 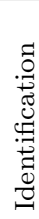 & $\begin{array}{l}\text { Z्च } \\
0 \\
\text { d } \\
0 \\
0 \\
0 \\
0 \\
\text { क }\end{array}$ & 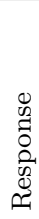 \\
\hline (Huchzermeier and Cohen 1996) & 1 & No & No & & $\checkmark$ & $\checkmark$ \\
\hline (Gupta, Maranas, and McDonald 2000) & 1 & No & No & & & $\checkmark$ \\
\hline (Mitra et al. 2008$)$ & 1 & No & No & & & $\checkmark$ \\
\hline (Guillén-Gosálbez and Grossmann 2010) & 1 & No & No & & & $\checkmark$ \\
\hline (Fang et al. 2013$)$ & 1 & No & No & & & $\checkmark$ \\
\hline (Pasandideh, Niaki, and Ásadi 2015) & 11 & No & No & & & $\checkmark$ \\
\hline (Scott et al. 2015$)$ & 1 & No & Yes & & & $\checkmark$ \\
\hline (Chibani et al. 2018) & 1 & No & No & & & $\checkmark$ \\
\hline (Liu et al. 2018) & 2 & No & No & & & $\checkmark$ \\
\hline (Quddus et al. 2018) & 1 & No & $\sim$ & & & $\checkmark$ \\
\hline
\end{tabular}

Table B5.: Fuzzy programming approaches to SCRM.

\begin{tabular}{|c|c|c|c|c|c|c|}
\hline Reference & 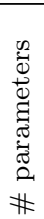 & 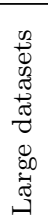 & 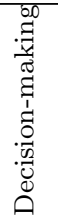 & 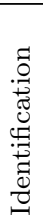 & 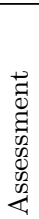 & 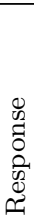 \\
\hline (Petrovic, Rov, and Petrovic 1998) & 2 & No & $\sim$ & & & $\checkmark$ \\
\hline (Petrovic, Roy, and Petrovic 1999$)$ & 2 & No & $\sim$ & & & $\checkmark$ \\
\hline (Petrovic 2001) & 3 & No & $\sim$ & & & $\checkmark$ \\
\hline (Giannoccaro, Pontrandolfo, and Scozzi 2003 ) & 2 & No & $\sim$ & & & $\checkmark$ \\
\hline (Chen and Lee 2004) & 2 & No & No & & & $\checkmark$ \\
\hline ( Wang and Shu 2005) & 4 & No & $\sim$ & & & $\checkmark$ \\
\hline (Amid, Ghodsvpour, and U'Brien 2006) & 3 & $\sim$ & No & & & $\checkmark$ \\
\hline (Kumar, Vrat, and Shankar 2006) & 4 & No & $\sim$ & & & $\checkmark$ \\
\hline (Xie, Petrovic, and Burnham 2006) & 1 & No & $\sim$ & & & $\checkmark$ \\
\hline (Peidro, Mula, and Poler 2007) & 11 & No & $\sim$ & & & $\checkmark$ \\
\hline (Selım and Uzkarahan 2008) & 1 & No & Yes & & & $\checkmark$ \\
\hline
\end{tabular}


Table B5.: (continued)

\begin{tabular}{|c|c|c|c|c|c|c|}
\hline Reference & 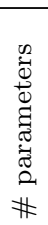 & 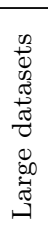 & 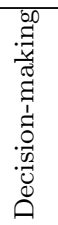 & 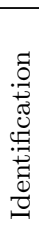 & 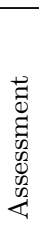 & 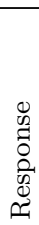 \\
\hline (Tang, Lau, and Ho 2008) & 1 & No & Yes & & $\checkmark$ & \\
\hline (Xu, Liu, and Wang 2008$)$ & 2 & No & $\sim$ & & & $\checkmark$ \\
\hline (Amid, Ghodsypour, and U Brien 2009) & 4 & No & $\sim$ & & & $\checkmark$ \\
\hline (IIitra et al. 2009$)$ & 2 & No & $\sim$ & & & $\checkmark$ \\
\hline (Peidro et al. 2009 ) & 11 & No & $\sim$ & & & $\checkmark$ \\
\hline (Xu, He, and Gen 2009) & 3 & No & $\sim$ & & & $\checkmark$ \\
\hline (Bilgen 2010) & 1 & No & $\sim$ & & & $\checkmark$ \\
\hline (Mula, Peidro, and Poler 2010 ) & 1 & No & No & & & $\checkmark$ \\
\hline (Peidro, Mula, and Poler 2010$)$ & 11 & No & $\sim$ & & & $\checkmark$ \\
\hline (Peidro et al. 2010$)$ & 11 & No & $\sim$ & & & $\checkmark$ \\
\hline (Pishvaee and Torabi 2010) & 28 & No & $\sim$ & & & $\checkmark$ \\
\hline (Q1n and $J_{1} 2010$ & 3 & No & No & & & $\checkmark$ \\
\hline ( $\overline{\mathrm{Wu}}$ et al. 2010$)$ & 11 & No & $\sim$ & & & $\checkmark$ \\
\hline (Haleh and Hamıdı 2011) & 9 & No & $\sim$ & & & $\checkmark$ \\
\hline (Kabak and lengin 2011) & 4 & No & $\sim$ & & & $\checkmark$ \\
\hline (Pishvaee and Razmi 2012 ) & 19 & No & $\sim$ & & & $\checkmark$ \\
\hline (Bouzembrak et al. 2013$)$ & 10 & No & $\sim$ & & & $\checkmark$ \\
\hline (Fazlollahtabar, Mahdavı, and Mohajerı 2013) & 5 & No & No & & & $\checkmark$ \\
\hline (Jouzdanı, Sadjadi, and Fathian 2013 ) & 8 & No & $\sim$ & & & $\checkmark$ \\
\hline (Tabrizi and Razmi 2013) & 11 & No & $\sim$ & & & $\checkmark$ \\
\hline (Wu et al. 2013$)$ & 8 & No & $\sim$ & & & $\checkmark$ \\
\hline (Jindal and Sangwan 2014) & 20 & $\sim$ & No & & & $\checkmark$ \\
\hline (Khalili-Damghani, Tavana, and Àmirkhan 2014) & 24 & No & $\sim$ & & & $\checkmark$ \\
\hline (I11chell, Mogre, and Perego 2014$)$ & 4 & No & Yes & & & $\checkmark$ \\
\hline (IMirakhorli 2014) & 2 & No & $\sim$ & & & $\checkmark$ \\
\hline (Özceylan and Paksoy 2014 ) & 17 & No & No & & & $\checkmark$ \\
\hline (Pishvaee, Razml, and Torabl 2014) & 54 & No & No & & & $\checkmark$ \\
\hline (Ramezanı et al. 2014$)$ & 37 & No & $\sim$ & & & $\checkmark$ \\
\hline (Tong et ai. 2014) & 4 & No & $\sim$ & & & $\checkmark$ \\
\hline (Vahdanı et al. 2014) & 32 & No & $\sim$ & & & $\checkmark$ \\
\hline (Yilmaz Balaman and Selım 2014) & 1 & No & $\sim$ & & & $\checkmark$ \\
\hline (" Hatef et al. 2015a) & 17 & No & No & & & $\checkmark$ \\
\hline Hateh et al. $2015 b)$ & 17 & No & No & & & $\checkmark$ \\
\hline (Moghaddam 2015) & 3 & No & $\sim$ & & & $\checkmark$ \\
\hline (Mousazadeh, Torabi, and Zahiri 2015 ) & 7 & No & No & & & $\checkmark$ \\
\hline (Salehi Sadghianı, Torabı, and Sahebiamnia 2015 ) & 4 & No & $\sim$ & & & $\checkmark$ \\
\hline (Subulan et al. 2015 ) & 15 & No & $\sim$ & & & $\checkmark$ \\
\hline (Torabi, Baghersad, and Mansouri 2015) & 7 & No & $\sim$ & & & $\checkmark$ \\
\hline (Yang, Liu, and Yang 2015) & 4 & No & $\sim$ & & & $\checkmark$ \\
\hline (Yang and Liu 2015) & 4 & No & $\sim$ & & & $\checkmark$ \\
\hline (Babazadeh et al. 2017 ) & 51 & No & $\sim$ & & & $\checkmark$ \\
\hline (Tsao et al. 2018) & 5 & No & $\mathrm{No}$ & & & $\checkmark$ \\
\hline
\end{tabular}

Table B6.: Hybrid mathematical programming approaches to SCRM.

\begin{tabular}{|c|c|c|c|c|c|c|}
\hline Reference & 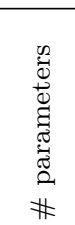 & 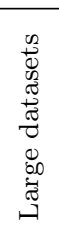 & 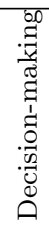 & 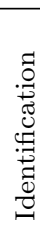 & $\begin{array}{l}\vec{Z} \\
\mathbb{0} \\
\mathbb{Z} \\
0 \\
0 \\
0 \\
0 \\
0 \\
0\end{array}$ & 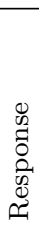 \\
\hline (Wu and Olson 2008) & 3 & No & $\sim$ & & & $\checkmark$ \\
\hline (Li and Zabinsky 2011$)$ & 2 & No & $\sim$ & & & $\checkmark$ \\
\hline (Pishvaee, Torabı, and Kazmi 2012) & 6 & No & $\sim$ & & & $\checkmark$ \\
\hline ("Tong, Feng, and Rong 2012 ) & 2 & No & No & & & $\checkmark$ \\
\hline (vahdanı et al. 2012) & 14 & No & $\sim$ & & & $\checkmark$ \\
\hline ( vahdanı et al. 2013) & 7 & No & $\sim$ & & & $\checkmark$ \\
\hline (Claypool, Norman, and Needy 2014 ) & 3 & No & $\sim$ & & & $\checkmark$ \\
\hline (Bal and Liu 2016) & 4 & No & $\sim$ & & & $\checkmark$ \\
\hline (Felfel, Ayadi, and Masmoudi 2016) & 1 & No & $\sim$ & & & $\checkmark$ \\
\hline (Keyvanshokooh, Ryan, and $\overline{K a b i r}$ 2016) & 3 & No & $\sim$ & & & $\checkmark$ \\
\hline (Zhalechian et al. 2016) & 29 & No & $\sim$ & & & $\checkmark$ \\
\hline (Zahırı and Pishvaee 2017$)$ & 15 & No & No & & & $\checkmark$ \\
\hline (Haddadsisakht and Ryan 2018 ) & 3 & No & No & & & $\checkmark$ \\
\hline (Jabbarzadeh, Fahımnia, and Sabouhı 2018) & 1 & No & $\sim$ & & & $\checkmark$ \\
\hline (Pavlov et al. 2018) & $\mathrm{N} / \mathrm{A}$ & No & $\sim$ & & $\checkmark$ & \\
\hline
\end{tabular}


Table B4.: Robust Optimisation approaches to SCRM

\begin{tabular}{|c|c|c|c|c|c|c|}
\hline Ref & 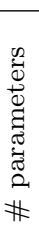 & 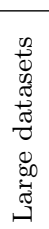 & 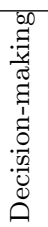 & 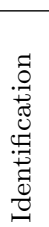 & 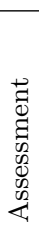 & 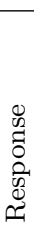 \\
\hline Aghezzaf 2005) & 1 & No & $\sim$ & & & $\checkmark$ \\
\hline (Soner Kara and Unut 2010) & 2 & No & $\sim$ & & & $\checkmark$ \\
\hline (Pan and Nagi 2010$)$ & 2 & No & $\sim$ & & & $\checkmark$ \\
\hline (Ben-Tal et al. 2011) & 1 & No & No & & & $\checkmark$ \\
\hline (Mirzapour Al-E-Hashem, Malekly, and Áryanezhad 2011) & 6 & No & $\sim$ & & & $\checkmark$ \\
\hline (Peng et al. 2011) & 1 & No & $\sim$ & & & $\checkmark$ \\
\hline (Pishvaee, Rabbani, and Torabi 2011) & 3 & $\sim$ & No & & & $\checkmark$ \\
\hline (Babazadeh and Razmı 2012) & 3 & No & No & & & $\checkmark$ \\
\hline (Hahn and Kuhn 2012) & 1 & No & Yes & & & $\checkmark$ \\
\hline (Hasani, Zegordi, and Nikbakhsh 2012) & 2 & No & $\sim$ & & & $\checkmark$ \\
\hline (Baghalian, Rezapour, and Farahani 2013) & 2 & No & No & & & $\checkmark$ \\
\hline (De Rosa et al. 2013$)$ & 2 & No & $\sim$ & & & $\checkmark$ \\
\hline (Ramezani, Bashiri, and Tavakkoli-Moghaddam 2013b) & 2 & No & No & & & $\checkmark$ \\
\hline (Hateh and Jolai 2014) & 3 & No & No & & & $\checkmark$ \\
\hline (Huang and Goetschalckx 2014) & 5 & No & No & & & $\checkmark$ \\
\hline (Jin et al. 2014 & 2 & No & No & & & $\checkmark$ \\
\hline (Kaya, Bagci, and Turkay 2014) & 2 & No & No & & & $\checkmark$ \\
\hline (Akbarı and Karımı 2015) & 1 & No & No & & & $\checkmark$ \\
\hline (Dubey, Gunasekaran, and Childe 2015 ) & 1 & $\sim$ & No & & & $\checkmark$ \\
\hline (Hasanı, Zegordi, and Nikbakhsh 2015) & 3 & No & $\sim$ & & & $\checkmark$ \\
\hline (Hasanı and Khosrojerdı 2016) & 2 & No & $\sim$ & & & $\checkmark$ \\
\hline (Govindan and Fattahi 2017) & 1 & No & No & & & $\checkmark$ \\
\hline (Zhang and Jiang 2017) & 1 & No & No & & & $\checkmark$ \\
\hline (Zokaee et al. 2017) & 8 & No & $\sim$ & & & $\checkmark$ \\
\hline (Buhayenko and den Hertog 2017) & 1 & No & $\sim$ & & & $\checkmark$ \\
\hline (Behzadı et al. 2018) & 5 & No & $\sim$ & & & $\checkmark$ \\
\hline (Jabbarzadeh, Haughton, and Khosrojerdi 2018) & 3 & No & $\sim$ & & & $\checkmark$ \\
\hline (Kim et al. 2018) & 3 & No & $\sim$ & & & $\checkmark$ \\
\hline (Prakash et al. 2018) & 2 & No & $\sim$ & & & $\checkmark$ \\
\hline (Rahmanı 2018) & 4 & No & $\sim$ & & & $\checkmark$ \\
\hline
\end{tabular}

\section{Additional References}

Aghezzaf, E. 2005. "Capacity planning and warehouse location in supply chains with uncertain demands." Journal of the Operational Research Society 56 (4): 453-462.

Ahmadi-Javid, A., and A.H. Seddighi. 2013. "A location-routing problem with disruption risk." Transportation Research Part E: Logistics and Transportation Review 53 (1): 63-82.

Akbari, A.A., and B. Karimi. 2015. "A new robust optimization approach for integrated multi-echelon, multi-product, multi-period supply chain network design under process uncertainty." International Journal of Advanced Manufacturing Technology 79 (1-4): 229-244.

Almansoori, A., and N. Shah. 2012. "Design and operation of a stochastic hydrogen supply chain network under demand uncertainty." International Journal of Hydrogen Energy 37 (5): 3965-3977.

Alonso-Ayuso, A., L.F. Escudero, A. Garn, M.T. Ortuño, and G. Pérez. 2003. "An approach for strategic supply chain planning under uncertainty based on stochastic 0-1 programming." Journal of Global Optimization 26 (1): 97-124.

Amid, A., S.H. Ghodsypour, and C. O'Brien. 2006. "Fuzzy multiobjective linear model for supplier selection in a supply chain." International Journal of Production Economics 104 (2): 394-407.

Amid, A., S.H. Ghodsypour, and C. O'Brien. 2009. "A weighted additive fuzzy multiobjective model for the supplier selection problem under price breaks in a supply Chain." International Journal of Production Economics 121 (2): 323-332.

Amin, S.H., and G. Zhang. 2013. "A multi-objective facility location model for closed-loop supply chain network under uncertain demand and return." Applied Mathematical Modelling 37 (6): 4165-4176. 
Awudu, I., and J. Zhang. 2013. "Stochastic production planning for a biofuel supply chain under demand and price uncertainties." Applied Energy 103: 189-196.

Ayvaz, B., B. Bolat, and N. Aydin. 2015. "Stochastic reverse logistics network design for waste of electrical and electronic equipment." Resources, Conservation and Recycling 104: 391-404.

Azaron, A., K.N. Brown, S.A. Tarim, and M. Modarres. 2008. "A multi-objective stochastic programming approach for supply chain design considering risk." International Journal of Production Economics 116 (1): 129-138.

Babazadeh, R., and J. Razmi. 2012. "A robust stochastic programming approach for agile and responsive logistics under operational and disruption risks." International Journal of Logistics Systems and Management 13 (4): 458-482.

Baghalian, A., S. Rezapour, and R.Z. Farahani. 2013. "Robust supply chain network design with service level against disruptions and demand uncertainties: A real-life case." European Journal of Operational Research 227 (1): 199-215.

Behzadi, G., M.J. O’Sullivan, T.L. Olsen, F. Scrimgeour, and A. Zhang. 2017. "Robust and resilient strategies for managing supply disruptions in an agribusiness supply chain." International Journal of Production Economics 191: 207-220.

Behzadi, G., M.J. OSullivan, T.L. Olsen, and A. Zhang. 2018. "Allocation flexibility for agribusiness supply chains under market demand disruption." International Journal of Production Research 56 (10): 3524-3546.

Ben-Tal, A., B.D. Chung, S.R. Mandala, and T. Yao. 2011. "Robust optimization for emergency logistics planning: Risk mitigation in humanitarian relief supply chains." Transportation Research Part B: Methodological 45 (8): 1177-1189.

Benyoucef, L., X. Xie, and G.A. Tanonkou. 2013. "Supply chain network design with unreliable suppliers: A Lagrangian relaxation-based approach." International Journal of Production Research 51 (21): 6435-6454.

Bidhandi, H. M., and R. M. Yusuff. 2011. "Integrated supply chain planning under uncertainty using an improved stochastic approach." Applied Mathematical Modelling 35 (6): 2618-2630.

Bilgen, B. 2010. "Application of fuzzy mathematical programming approach to the production allocation and distribution supply chain network problem." Expert Systems with Applications 37 (6): 4488-4495.

Bonfill, A., A. Espuña, and L. Puigjaner. 2008. "Proactive approach to address the uncertainty in short-term scheduling." Computers and Chemical Engineering 32 (8): 1689-1706.

Bouzembrak, Y., H. Allaoui, G. Goncalves, H. Bouchriha, and M. Baklouti. 2013. "A possibilistic linear programming model for supply chain network design under uncertainty." IMA Journal of Management Mathematics 24 (2): 209-229.

Buhayenko, Viktoryia, and Dick den Hertog. 2017. "Adjustable Robust Optimisation approach to optimise discounts for multi-period supply chain coordination under demand uncertainty." International Journal of Production Research 55 (22): 6801-6823.

Cardona-Valdés, Y., A. Álvarez, and D. Ozdemir. 2011. "A bi-objective supply chain design problem with uncertainty." Transportation Research Part C: Emerging Technologies 19 (5): 821-832.

Cardona-Valdés, Y., A. Álvarez, and J. Pacheco. 2014. "Metaheuristic procedure for a biobjective supply chain design problem with uncertainty." Transportation Research Part B: Methodological 60: 66-84.

Cardoso, S.R., A.P.F.D. Barbosa-Pvoa, and S. Relvas. 2013. "Design and planning of supply chains with integration of reverse logistics activities under demand uncertainty." European Journal of Operational Research 226 (3): 436-451.

Chan, Y., W.B. Carter, and M.D. Burnes. 2001. "A multiple-depot, multiple-vehicle, locationrouting problem with stochastically processed demands." Computers and Operations Research 28 (8): 803-826.

Chatzikontidou, A., P. Longinidis, P. Tsiakis, and M.C. Georgiadis. 2017. "Flexible supply chain network design under uncertainty." Chemical Engineering Research and Design 128: $290-305$. 
Chen, C.-L., and W.-C. Lee. 2004. "Multi-objective optimization of multi-echelon supply chain networks with uncertain product demands and prices." Computers and Chemical Engineering 28 (6-7): 1131-1144.

Chen, C.-W., and Y. Fan. 2012. "Bioethanol supply chain system planning under supply and demand uncertainties." Transportation Research Part E: Logistics and Transportation Review 48 (1): 150-164.

Chibani, Akram, Xavier Delorme, Alexandre Dolgui, and Henri Pierreval. 2018. "Dynamic optimisation for highly agile supply chains in e-procurement context." International Journal of Production Research 0 (0): 1-26.

Cui, T., Y. Ouyang, and Z.-J.M. Shen. 2010. "Reliable facility location design under the risk of disruptions." Operations Research 58 (4 PART 1): 998-1011.

Dayhim, M., M.A. Jafari, and M. Mazurek. 2014. "Planning sustainable hydrogen supply chain infrastructure with uncertain demand." International Journal of Hydrogen Energy 39 (13): 6789-6801.

De Rosa, V., M. Gebhard, E. Hartmann, and J. Wollenweber. 2013. "Robust sustainable bidirectional logistics network design under uncertainty." International Journal of Production Economics 145 (1): 184-198.

Fattahi, M., M. Mahootchi, S.M. Moattar Husseini, E. Keyvanshokooh, and F. Alborzi. 2015. "Investigating replenishment policies for centralised and decentralised supply chains using stochastic programming approach." International Journal of Production Research 53 (1): 41-69.

Fazlollahtabar, H., I. Mahdavi, and A. Mohajeri. 2013. "Applying fuzzy mathematical programming approach to optimize a multiple supply network in uncertain condition with comparative analysis." Applied Soft Computing Journal 13 (1): 550-562.

Franca, R.B., E.C. Jones, C.N. Richards, and J.P. Carlson. 2010. "Multi-objective stochastic supply chain modeling to evaluate tradeoffs between profit and quality." International Journal of Production Economics 127 (2): 292-299.

Gaonkar, R.S., and N. Viswanadham. 2007. "Analytical framework for the management of risk in supply chains." IEEE Transactions on Automation Science and Engineering 4 (2): 265-273.

Gebreslassie, B.H., Y. Yao, and F. You. 2012. "Design under uncertainty of hydrocarbon biorefinery supply chains: Multiobjective stochastic programming models, decomposition algorithm, and a Comparison between CVaR and downside risk." AIChE Journal 58 (7): 2155-2179.

Georgiadis, M.C., P. Tsiakis, P. Longinidis, and M.K. Sofioglou. 2011. "Optimal design of supply chain networks under uncertain transient demand variations." Omega 39 (3): 254272.

Giannoccaro, I., P. Pontrandolfo, and B. Scozzi. 2003. "A fuzzy echelon approach for inventory management in supply chains." European Journal of Operational Research 149 (1): 185-196.

Giarola, S., N. Shah, and F. Bezzo. 2012. "A comprehensive approach to the design of ethanol supply chains including carbon trading effects." Bioresource Technology 107: 175-185.

Goh, M., J.Y.S. Lim, and F. Meng. 2007. "A stochastic model for risk management in global supply chain networks." European Journal of Operational Research 182 (1): 164-173.

Govindan, K., and M. Fattahi. 2017. "Investigating risk and robustness measures for supply chain network design under demand uncertainty: A case study of glass supply chain." International Journal of Production Economics 183: 680-699.

Govindan, K., A. Jafarian, and V. Nourbakhsh. 2015. "Bi-objective integrating sustainable order allocation and sustainable supply chain network strategic design with stochastic demand using a novel robust hybrid multi-objective metaheuristic." Computers and Operations Research 62: 112-130.

Guillén, G., A. Espuña, and L. Puigjaner. 2006. "Addressing the scheduling of chemical supply chains under demand uncertainty." AIChE Journal 52 (11): 3864-3881.

Guillén, G., F.D. Mele, M. Bagajewicz, A. Espuña, and L. Puigjaner. 2003. "Management of financial and consumer satisfaction risks in supply chain design." Computer Aided Chemical 
Engineering $14(\mathrm{C}):$ 419-424.

Guillén, G., F.D. Mele, M.J. Bagajewicz, A. Espuña, and L. Puigjaner. 2005. "Multiobjective supply chain design under uncertainty." Chemical Engineering Science 60 (6): 1535-1553.

Guillén, G., F.D. Mele, A. Espuña, and L. Puigjaner. 2006. "Addressing the design of chemical supply chains under demand uncertainty." Industrial and Engineering Chemistry Research 45 (22): 7566-7581.

Guillén-Gosálbez, G., and I.E. Grossmann. 2009. "Optimal design and planning of sustainable chemical supply chains under uncertainty." AIChE Journal 55 (1): 99-121.

Gupta, A., and C.D. Maranas. 2000. "A two-stage modeling and solution framework for multisite midterm planning under demand uncertainty." Industrial and Engineering Chemistry Research 39 (10): 3799-3813.

Haleh, H., and A. Hamidi. 2011. "A fuzzy MCDM model for allocating orders to suppliers in a supply chain under uncertainty over a multi-period time horizon." Expert Systems with Applications 38 (8): 9076-9083.

Han, C., and M. Damrongwongsiri. 2005. "Stochastic modeling of a two-echelon multiple sourcing supply chain system with genetic algorithm." Journal of Manufacturing Technology Management 16 (1): 87-108.

Hasani, A., and A. Khosrojerdi. 2016. "Robust global supply chain network design under disruption and uncertainty considering resilience strategies: A parallel memetic algorithm for a real-life case study." Transportation Research Part E: Logistics and Transportation Review 87: 20-52.

Hasani, A., S.H. Zegordi, and E. Nikbakhsh. 2012. "Robust closed-loop supply chain network design for perishable goods in agile manufacturing under uncertainty." International Journal of Production Research 50 (16): 4649-4669.

Hasani, A., S.H. Zegordi, and E. Nikbakhsh. 2015. "Robust closed-loop global supply chain network design under uncertainty: The case of the medical device industry." International Journal of Production Research 53 (5): 1596-1624.

Hatefi, S.M., and F. Jolai. 2014. "Robust and reliable forward-reverse logistics network design under demand uncertainty and facility disruptions." Applied Mathematical Modelling 38 (9-10): 2630-2647.

Hatefi, S.M., F. Jolai, S.A. Torabi, and R. Tavakkoli-Moghaddam. 2015a. "A credibilityconstrained programming for reliable forward-reverse logistics network design under uncertainty and facility disruptions." International Journal of Computer Integrated Manufacturing 28 (6): 664-678.

Hatefi, S.M., F. Jolai, S.A. Torabi, and R. Tavakkoli-Moghaddam. 2015b. "Reliable design of an integrated forward-revere logistics network under uncertainty and facility disruptions: A fuzzy possibilistic programing model." KSCE Journal of Civil Engineering 19 (4): 11171128 .

Hnaien, F., X. Delorme, and A. Dolgui. 2010. "Multi-objective optimization for inventory control in two-level assembly systems under uncertainty of lead times." Computers and Operations Research 37 (11): 1835-1843.

Hnaien, Faicel, Alexandre Dolgui, and Desheng Dash Wu. 2016. "Single-period inventory model for one-level assembly system with stochastic lead times and demand." International Journal of Production Research 54 (1): 186-203.

Huang, E., and M. Goetschalckx. 2014. "Strategic robust supply chain design based on the Pareto-optimal tradeoff between efficiency and risk." European Journal of Operational Research 237 (2): 508-518.

Jabbarzadeh, Armin, Michael Haughton, and Amir Khosrojerdi. 2018. "Closed-loop supply chain network design under disruption risks: A robust approach with real world application." Computers and Industrial Engineering 116: 178 - 191.

Jalali, Sajjad, Mehdi Seifbarghy, and Seyed Taghi Akhavan Niaki. 2018. "A risk-averse location-protection problem under intentional facility disruptions: A modified hybrid decomposition algorithm." Transportation Research Part E: Logistics and Transportation Review 114: $196-219$ 
Jeong, K.-Y., J.-D. Hong, and Y. Xie. 2014. "Design of emergency logistics networks, taking efficiency, risk and robustness into consideration." International Journal of Logistics Research and Applications 17 (1): 1-22.

Jerbia, Rim, Mouna Kchaou Boujelben, Mohamed Amine Sehli, and Zied Jemai. 2018. "A stochastic closed-loop supply chain network design problem with multiple recovery options." Computers and Industrial Engineering 118: 23 - 32.

Jin, M., R. Ma, L. Yao, and P. Ren. 2014. "An effective heuristic algorithm for robust supply chain network design under uncertainty." Applied Mathematics and Information Sciences 8 (2): 819-826.

Jindal, A., and K.S. Sangwan. 2014. "Closed loop supply chain network design and optimisation using fuzzy mixed integer linear programming model." International Journal of Production Research 52 (14): 4156-4173.

Jouzdani, J., S.J. Sadjadi, and M. Fathian. 2013. "Dynamic dairy facility location and supply chain planning under traffic congestion and demand uncertainty: A case study of Tehran." Applied Mathematical Modelling 37 (18-19): 8467-8483.

Kabak, O., and F. lengin. 2011. "Possibilistic linear-programming approach for supply chain networking decisions." European Journal of Operational Research 209 (3): 253-264.

Kamalahmadi, M., and M.M. Parast. 2017. "An assessment of supply chain disruption mitigation strategies." International Journal of Production Economics 184: 210-230.

Kara, S.S., and S. Onut. 2010. "A two-stage stochastic and robust programming approach to strategic planning of a reverse supply network: The case of paper recycling." Expert Systems with Applications 37 (9): 6129-6137.

Kaya, O., F. Bagci, and M. Turkay. 2014. "Planning of capacity, production and inventory decisions in a generic reverse supply chain under uncertain demand and returns." International Journal of Production Research 52 (1): 270-282.

Kazemzadeh, N., and G. Hu. 2013. "Optimization models for biorefinery supply chain network design under uncertainty." Journal of Renewable and Sustainable Energy 5 (5).

Khalili-Damghani, K., M. Tavana, and M. Amirkhan. 2014. "A fuzzy bi-objective mixed-integer programming method for solving supply chain network design problems under ambiguous and vague conditions." International Journal of Advanced Manufacturing Technology 73 (9-12): 1567-1595.

Khatami, M., M. Mahootchi, and R.Z. Farahani. 2015. "Benders' decomposition for concurrent redesign of forward and closed-loop supply chain network with demand and return uncertainties." Transportation Research Part E: Logistics and Transportation Review 79: $1-21$.

Kilic, Y.E., and U.R. Tuzkaya. 2015. "A two-stage stochastic mixed-integer programming approach to physical distribution network design." International Journal of Production Research 53 (4): 1291-1306.

Kim, J., M.J. Realff, and J.H. Lee. 2011. "Optimal design and global sensitivity analysis of biomass supply chain networks for biofuels under uncertainty." Computers and Chemical Engineering 35 (9): 1738-1751.

Kim, Joonrak, Byung Do Chung, Yuncheol Kang, and Bongju Jeong. 2018. "Robust optimization model for closed-loop supply chain planning under reverse logistics flow and demand uncertainty." Journal of Cleaner Production 196: 1314 - 1328.

Kiya, F., and H. Davoudpour. 2012. "Stochastic programming approach to re-designing a warehouse network under uncertainty." Transportation Research Part E: Logistics and Transportation Review 48 (5): 919-936.

Klibi, W., and A. Martel. 2012. "Modeling approaches for the design of resilient supply networks under disruptions." International Journal of Production Economics 135 (2): 882-898.

Kumar, M., P. Vrat, and R. Shankar. 2006. "A fuzzy programming approach for vendor selection problem in a supply chain." International Journal of Production Economics 101 (2): 273-285.

Kumar, S.K., and M.K. Tiwari. 2013. "Supply chain system design integrated with risk pooling." Computers and Industrial Engineering 64 (2): 580-588. 
Kumar, S.K., M.K. Tiwari, and R.F. Babiceanu. 2010. "Minimisation of supply chain cost with embedded risk using computational intelligence approaches." International Journal of Production Research 48 (13): 3717-3739.

Lababidi, H.M.S., M.A. Ahmed, I.M. Alatiqi, and A.F. Al-Enzi. 2004. "Optimizing the Supply Chain of a Petrochemical Company under Uncertain Operating and Economic Conditions." Industrial and Engineering Chemistry Research 43 (1): 63-73.

Lee, D.-H., and M. Dong. 2009. "Dynamic network design for reverse logistics operations under uncertainty." Transportation Research Part E: Logistics and Transportation Review 45 (1): $61-71$.

Lee, D.-H., M. Dong, and W. Bian. 2010. "The design of sustainable logistics network under uncertainty." International Journal of Production Economics 128 (1): 159-166.

Lee, D.-H., M. Dong, W. Bian, and Y.-J. Tseng. 2007. "Design of product recovery networks under uncertainty." Transportation Research Record (2008): 19-25.

Levis, A.A., and L.G. Papageorgiou. 2004. "A hierarchical solution approach for multi-site capacity planning under uncertainty in the pharmaceutical industry." Computers and Chemical Engineering 28 (5): 707-725.

Li, Q., and G. Hu. 2014. "Supply chain design under uncertainty for advanced biofuel production based on bio-oil gasification." Energy 74 (C): 576-584.

Lieckens, K., and N. Vandaele. 2007. "Reverse logistics network design with stochastic lead times." Computers and Operations Research 34 (2): 395-416.

Lin, C.-W.R., and H.-Y.S. Chen. 2003. "Dynamic allocation of uncertain supply for the perishable commodity supply chain." International Journal of Production Research 41 (13): 3119-3138.

Liu, Ming, Rongfan Liu, Zhanguo Zhu, Chengbin Chu, and Xiaoyi Man. 2018. "A BiObjective Green Closed Loop Supply Chain Design Problem with Uncertain Demand." Sustainabilauthor = "Abroon Qazi and Alex Dickson and John Quigley and Barbara Gaudenzi", you2009ity 10 (4).

Liu, S., N. Shah, and L.G. Papageorgiou. 2012. "Multiechelon supply chain planning with sequence-dependent changeovers and price elasticity of demand under uncertainty." AIChE Journal 58 (11): 3390-3403.

Liu, Y., and B. Guo. 2014. "A lexicographic approach to postdisaster relief logistics planning considering fill rates and costs under uncertainty." Mathematical Problems in Engineering 2014

Longinidis, P., and M.C. Georgiadis. 2011. "Integration of financial statement analysis in the optimal design of supply chain networks under demand uncertainty." International Journal of Production Economics 129 (2): 262-276.

Longinidis, P., and M.C. Georgiadis. 2013. "Managing the trade-offs between financial performance and credit solvency in the optimal design of supply chain networks under economic uncertainty." Computers and Chemical Engineering 48: 264-279.

Lucas, C., S.A. Mirhassani, G. Mitra, and C.A. Poojari. 2001. "An application of Lagrangian relaxation to a capacity planning problem under uncertainty." Journal of the Operational Research Society 52 (11): 1256-1266.

Madadi, A., M.E. Kurz, S.J. Mason, and K.M. Taaffe. 2014a. "Supply chain design under quality disruptions and tainted materials delivery." Transportation Research Part E: Logistics and Transportation Review 67: 105-123.

Madadi, A., M.E. Kurz, K.M. Taaffe, J.L. Sharp, and S.J. Mason. 2014b. "Supply network design: Risk-averse or risk-neutral?" Computers and Industrial Engineering 78: 55-65.

Mak, H.-Y., and Z.-J. Shen. 2012. "Risk diversification and risk pooling in supply chain design." IIE Transactions 44 (8): 603-621.

Mari, S.I., Y.H. Lee, and M.S. Memon. 2014. "Sustainable and resilient supply chain network design under disruption risks." Sustainability 6 (10): 6666-6686.

Meena, P.L., and S.P. Sarmah. 2013. "Multiple sourcing under supplier failure risk and quantity discount: A genetic algorithm approach." Transportation Research Part E: Logistics and Transportation Review 50 (1): 84-97. 
Mirakhorli, A. 2014. "Fuzzy multi-objective optimization for closed loop logistics network design in bread-producing industries." International Journal of Advanced Manufacturing Technology 70 (1-4): 349-362.

Miranda, P.A., and R.A. Garrido. 2004. "Incorporating inventory control decisions into a strategic distribution network design model with stochastic demand." Transportation Research Part E: Logistics and Transportation Review 40 (3): 183-207.

Miranda, P.A., and R.A. Garrido. 2008. "Valid inequalities for Lagrangian relaxation in an inventory location problem with stochastic capacity." Transportation Research Part E: Logistics and Transportation Review 44 (1): 47-65.

Mirzapour Al-E-Hashem, S.M.J., H. Malekly, and M.B. Aryanezhad. 2011. "A multi-objective robust optimization model for multi-product multi-site aggregate production planning in a supply chain under uncertainty." International Journal of Production Economics 134 (1): $28-42$.

Mitra, K., R.D. Gudi, S.C. Patwardhan, and G. Sardar. 2009. "Towards resilient supply chains: Uncertainty analysis using fuzzy mathematical programming." Chemical Engineering Research and Design 87 (7): 967-981.

Moghaddam, K.S. 2015. "Fuzzy multi-objective model for supplier selection and order allocation in reverse logistics systems under supply and demand uncertainty." Expert Systems with Applications 42 (15-16): 6237-6254.

Mousazadeh, M., S.A. Torabi, and B. Zahiri. 2015. "A robust possibilistic programming approach for pharmaceutical supply chain network design." Computers and Chemical Engineering 82: 115-128.

Mula, J., D. Peidro, and R. Poler. 2010. "The effectiveness of a fuzzy mathematical programming approach for supply chain production planning with fuzzy demand." International Journal of Production Economics 128 (1): 136-143.

Namdar, Jafar, Xueping Li, Rupy Sawhney, and Ninad Pradhan. 2018. "Supply chain resilience for single and multiple sourcing in the presence of disruption risks." International Journal of Production Research 56 (6): 2339-2360.

Nasiri, G.R., R. Zolfaghari, and H. Davoudpour. 2014. "An integrated supply chain productiondistribution planning with stochastic demands." Computers and Industrial Engineering 77: $35-45$.

Nickel, S., F. Saldanha-da Gama, and H.-P. Ziegler. 2012. "A multi-stage stochastic supply network design problem with financial decisions and risk management." Omega 40 (5): 511524.

Nooraie, S.V., and M. M. Parast. 2015. "A multi-objective approach to supply chain risk management: Integrating visibility with supply and demand risk." International Journal of Production Economics 161: 192-200.

Noyan, N. 2012. "Risk-averse two-stage stochastic programming with an application to disaster management." Computers and Operations Research 39 (3): 541-559.

Oliveira, F., V. Gupta, S. Hamacher, and I.E. Grossmann. 2013. "A Lagrangean decomposition approach for oil supply chain investment planning under uncertainty with risk considerations." Computers and Chemical Engineering 50: 184-195.

Özceylan, E., and T. Paksoy. 2014. "Interactive fuzzy programming approaches to the strategic and tactical planning of a closed-loop supply chain under uncertainty." International Journal of Production Research 52 (8): 2363-2387.

Pan, F., and R. Nagi. 2010. "Robust supply chain design under uncertain demand in agile manufacturing." Computers and Operations Research 37 (4): 668-683.

Pariazar, Mahmood, and Mustafa Y. Sir. 2018. "A multi-objective approach for supply chain design considering disruptions impacting supply availability and quality." Computers and Industrial Engineering 121: 113 - 130.

Park, S., T.-E. Lee, and C.S. Sung. 2010. "A three-level supply chain network design model with risk-pooling and lead times." Transportation Research Part E: Logistics and Transportation Review 46 (5): 563-581.

Peidro, D., J. Mula, M. Jiménez, and M. del Mar Botella. 2010. "A fuzzy linear programming 
based approach for tactical supply chain planning in an uncertainty environment." European Journal of Operational Research 205 (1): 65-80.

Peidro, D., J. Mula, and R. Poler. 2007. "Supply chain planning under uncertainty: A fuzzy linear programming approach." In IEEE International Conference on Fuzzy Systems, 1-6.

Peidro, D., J. Mula, and R. Poler. 2010. "Fuzzy linear programming for supply chain planning under uncertainty." International Journal of Information Technology and Decision Making 9 (3): 373-392.

Peidro, D., J. Mula, R. Poler, and J.-L. Verdegay. 2009. "Fuzzy optimization for supply chain planning under supply, demand and process uncertainties." Fuzzy Sets and Systems 160 (18): 2640-2657.

Peng, P., L.V. Snyder, A. Lim, and Z. Liu. 2011. "Reliable logistics networks design with facility disruptions." Transportation Research Part B: Methodological 45 (8): 1190-1211.

Petrovic, D. 2001. "Simulation of supply chain behaviour and performance in an uncertain environment." International Journal of Production Economics 71 (1-3): 429-438.

Petrovic, D., R. Roy, and R. Petrovic. 1998. "Modelling and simulation of a supply chain in an uncertain environment." European Journal of Operational Research 109 (2): 299-309.

Petrovic, D., R. Roy, and R. Petrovic. 1999. "Supply chain modelling using fuzzy sets." International Journal of Production Economics 59 (1): 443-453.

Pimentel, B.S., G.R. Mateus, and F.A. Almeida. 2013. "Stochastic capacity planning and dynamic network design." International Journal of Production Economics 145 (1): 139149.

Pishvaee, M.S., and J. Razmi. 2012. "Environmental supply chain network design using multiobjective fuzzy mathematical programming." Applied Mathematical Modelling 36 (8): 3433 3446.

Pishvaee, M.S., and S.A. Torabi. 2010. "A possibilistic programming approach for closed-loop supply chain network design under uncertainty." Fuzzy Sets and Systems 161 (20): 26682683.

Poojari, C.A., C. Lucas, and G. Mitra. 2008. "Robust solutions and risk measures for a supply chain planning problem under uncertainty." Journal of the Operational Research Society 59 (1): $2-12$.

Prakash, Surya, Sameer Kumar, Gunjan Soni, Vipul Jain, and Ajay Pal Singh Rathore. 2018. "Closed-loop supply chain network design and modelling under risks and demand uncertainty: an integrated robust optimization approach." Annals of Operations Research .

PrasannaVenkatesan, S., and M. Goh. 2016. "Multi-objective supplier selection and order allocation under disruption risk." Transportation Research Part E: Logistics and Transportation Review 95: 124-142.

PrasannaVenkatesan, S., and S. Kumanan. 2012. "Multi-objective supply chain sourcing strategy design under risk using PSO and simulation." International Journal of Advanced Manufacturing Technology 61 (1-4): 325-337.

Qi, L., and Z.-J.M. Shen. 2007. "A supply chain design model with unreliable supply." Naval Research Logistics 54 (8): 829-844.

Qi, L., Z.-J.M. Shen, and L.V. Snyder. 2010. "The effect of supply disruptions on supply chain design decisions." Transportation Science 44 (2): 274-289.

Qin, X., X. Liu, and L. Tang. 2013. "A two-stage stochastic mixed-integer program for the capacitated logistics fortification planning under accidental disruptions." Computers and Industrial Engineering 65 (4): 614-623.

Qin, Z., and X. Ji. 2010. "Logistics network design for product recovery in fuzzy environment." European Journal of Operational Research 202 (2): 479-490.

Quddus, Md Abdul, Sudipta Chowdhury, Mohammad Marufuzzaman, Fei Yu, and Linkan Bian. 2018. "A two-stage chance-constrained stochastic programming model for a bio-fuel supply chain network." International Journal of Production Economics 195: 27 - 44.

Rahimi, Mohsen, and Vahidreza Ghezavati. 2018. "Sustainable multi-period reverse logistics network design and planning under uncertainty utilizing conditional value at risk (CVaR) for recycling construction and demolition waste." Journal of Cleaner Production 172: 1567 
$-1581$.

Rahmani, Donya. 2018. "Designing a robust and dynamic network for the emergency blood supply chain with the risk of disruptions." Annals of Operations Research .

Rajgopal, J., Z. Wang, A.J. Schaefer, and O.A. Prokopyev. 2011. "Integrated design and operation of remnant inventory supply chains under uncertainty." European Journal of Operational Research 214 (2): 358-364.

Ramezani, M., M. Bashiri, and R. Tavakkoli-Moghaddam. 2013a. "A new multi-objective stochastic model for a forward/reverse logistic network design with responsiveness and quality level." Applied Mathematical Modelling 37 (1-2): 328-344.

Ramezani, M., M. Bashiri, and R. Tavakkoli-Moghaddam. 2013b. "A robust design for a closedloop supply chain network under an uncertain environment." International Journal of Advanced Manufacturing Technology 66 (5-8): 825-843.

Ramezani, M., A.M. Kimiagari, B. Karimi, and T.H. Hejazi. 2014. "Closed-loop supply chain network design under a fuzzy environment." Knowledge-Based Systems 59: 108-120.

Rayat, F., M. Musavi, and A. Bozorgi-Amiri. 2017. "Bi-objective reliable location-inventoryrouting problem with partial backordering under disruption risks: A modified AMOSA approach." Applied Soft Computing Journal 59: 622-643. Cited By 0.

Ruiz-Femenia, R., G. Guillén-Gosálbez, L. Jiménez, and J.A. Caballero. 2013. "Multi-objective optimization of environmentally conscious chemical supply chains under demand uncertainty." Chemical Engineering Science 95: 1-11.

Sabio, N., M. Gadalla, G. Guillén-Gosálbez, and L. Jiménez. 2010. "Strategic planning with risk control of hydrogen supply chains for vehicle use under uncertainty in operating costs: A case study of Spain." International Journal of Hydrogen Energy 35 (13): 6836-6852.

Salehi Sadghiani, N., S.A. Torabi, and N. Sahebjamnia. 2015. "Retail supply chain network design under operational and disruption risks." Transportation Research Part E: Logistics and Transportation Review 75: 95-114.

Salema, M.I.G., A.P. Barbosa-Povoa, and A.Q. Novais. 2007. "An optimization model for the design of a capacitated multi-product reverse logistics network with uncertainty." European Journal of Operational Research 179 (3): 1063-1077.

Santoso, T., S. Ahmed, M. Goetschalckx, and A. Shapiro. 2005. "A stochastic programming approach for supply chain network design under uncertainty." European Journal of Operational Research 167 (1): 96-115.

Sawik, T. 2011. "Selection of supply portfolio under disruption risks." Omega 39 (2): 194-208.

Sawik, T. 2013. "Selection of resilient supply portfolio under disruption risks." Omega 41 (2): 259-269.

Sawik, T. 2014. "On the robust decision-making in a supply chain under disruption risks." International Journal of Production Research 52 (22): 6760-6781.

Sawik, T. 2015. "On the fair optimization of cost and customer service level in a supply chain under disruption risks." Omega 53: 58-66.

Sawik, Tadeusz. 2016. "On the risk-averse optimization of service level in a supply chain under disruption risks." International Journal of Production Research 54 (1): 98-113.

Sawik, Tadeusz. 2018. "Selection of a dynamic supply portfolio under delay and disruption risks." International Journal of Production Research 56 (1-2): 760-782.

Sharifzadeh, M., M.C. Garcia, and N. Shah. 2015. "Supply chain network design and operation: Systematic decision-making for centralized, distributed, and mobile biofuel production using mixed integer linear programming (MILP) under uncertainty." Biomass and Bioenergy 81: 401-414.

Shimizu, Y., H. Fushimi, and T. Wada. 2011. "Robust logistics network modeling and design against uncertainties." Journal of Advanced Mechanical Design, Systems and Manufacturing 5 (2): 103-114.

Shu, J., Q. Ma, and S. Li. 2010. "Integrated location and two-echelon inventory network design under uncertainty." Annals of Operations Research 181 (1): 233-247.

Shukla, A., V.A. Lalit, and V. Venkatasubramanian. 2011. "Optimizing efficiency-robustness trade-offs in supply chain design under uncertainty due to disruptions." International Jour- 
nal of Physical Distribution and Logistics Management 41 (6): 623-646.

Singh, A.R., R. Jain, and P.K. Mishra. 2013. "Capacities-based supply chain network design considering demand uncertainty using two-stage stochastic programming." International Journal of Advanced Manufacturing Technology 69 (1-4): 555-562.

Sodhi, M.S., and C.S. Tang. 2009. "Modeling supply-chain planning under demand uncertainty using stochastic programming: A survey motivated by asset-liability management." International Journal of Production Economics 121 (2): 728-738.

Soleimani, H., and K. Govindan. 2014. "Reverse logistics network design and planning utilizing conditional value at risk." European Journal of Operational Research 237 (2): 487-497.

Soleimani, H., M. Seyyed-Esfahani, and G. Kannan. 2014. "Incorporating risk measures in closed-loop supply chain network design." International Journal of Production Research 52 (6): 1843-1867.

Soner Kara, S., and S. Onut. 2010. "A stochastic optimization approach for paper recycling reverse logistics network design under uncertainty." International Journal of Environmental Science and Technology 7 (4): 717-730.

Song, Ju Myung, Weiwei Chen, and Lei Lei. 2018. "Supply chain flexibility and operations optimisation under demand uncertainty: a case in disaster relief." International Journal of Production Research 56 (10): 3699-3713.

Subulan, K., A. Baykasolu, F.B. Özsoydan, A.S. Taan, and H. Selim. 2015. "A case-oriented approach to a lead/acid battery closed-loop supply chain network design under risk and uncertainty." Journal of Manufacturing Systems 37: 340-361.

Tabrizi, B.H., and J. Razmi. 2013. "Introducing a mixed-integer non-linear fuzzy model for risk management in designing supply chain networks." Journal of Manufacturing Systems 32 (2): 295-307.

Taleizadeh, A.A., S.T.A. Niaki, and F. Barzinpour. 2011. "Multiple-buyer multiple-vendor multi-product multi-constraint supply chain problem with stochastic demand and variable lead-time: A harmony search algorithm." Applied Mathematics and Computation 217 (22): 9234-9253.

Tapiero, C.S., and A. Grando. 2006. "Supply risk and inventory outsourcing." Production Planning and Control 17 (5): 534-539.

Tong, K., M.J. Gleeson, G. Rong, and F. You. 2014. "Optimal design of advanced dropin hydrocarbon biofuel supply chain integrating with existing petroleum refineries under uncertainty." Biomass and Bioenergy 60: 108-120.

Torabi, S.A., M. Baghersad, and S.A. Mansouri. 2015. "Resilient supplier selection and order allocation under operational and disruption risks." Transportation Research Part E: Logistics and Transportation Review 79: 22-48.

Tsao, Yu-Chung, Vo-Van Thanh, Jye-Chyi Lu, and Vincent Yu. 2018. "Designing sustainable supply chain networks under uncertain environments: Fuzzy multi-objective programming." Journal of Cleaner Production 174: 1550 - 1565.

Vahdani, B., S. Dehbari, M. Naderi-Beni, and E. Zeinali Kh. 2014. "An artificial intelligence approach for fuzzy possibilistic-stochastic multi-objective logistics network design." Neural Computing and Applications 25 (7-8): 1887-1902.

Wang, J., and Y.-F. Shu. 2005. "Fuzzy decision modeling for supply chain management." Fuzzy Sets and Systems 150 (1): 107-127.

Weskamp, Christoph, Achim Koberstein, Frank Schwartz, Leena Suhl, and Stefan Voss. 2018. "A two-stage stochastic programming approach for identifying optimal postponement strategies in supply chains with uncertain demand." Omega .

Wu, D.D., Y. Zhang, D. Wu, and D.L. Olson. 2010. "Fuzzy multi-objective programming for supplier selection and risk modeling: A possibility approach." European Journal of Operational Research 200 (3): 774-787.

Wu, Dexiang, Desheng Dash Wu, Yidong Zhang, and David L. Olson. 2013. "Supply chain outsourcing risk using an integrated stochastic-fuzzy optimization approach." Inf. Sci. 235: $242-258$.

Xie, Fei, and Yongxi Huang. 2018. "A multistage stochastic programming model for a multi- 
period strategic expansion of biofuel supply chain under evolving uncertainties." Transportation Research Part E: Logistics and Transportation Review 111: 130 - 148.

Xie, Y., D. Petrovic, and K. Burnham. 2006. "A heuristic procedure for the two-level control of serial supply chains under fuzzy customer demand." International Journal of Production Economics 102 (1): 37-50.

$\mathrm{Xu}, \mathrm{J} ., \mathrm{Y}$. He, and M. Gen. 2009. "A class of random fuzzy programming and its application to supply chain design." Computers and Industrial Engineering 56 (3): 937-950.

$\mathrm{Xu}$, J., Q. Liu, and R. Wang. 2008. "A class of multi-objective supply chain networks optimal model under random fuzzy environment and its application to the industry of Chinese liquor." Information Sciences 178 (8): 2022-2043.

Yang, G.-Q., and Y.-K. Liu. 2015. "Designing fuzzy supply chain network problem by meanrisk optimization method." Journal of Intelligent Manufacturing 26 (3): 447-458.

Yang, G.-Q., Y.-K. Liu, and K. Yang. 2015. "Multi-objective biogeography-based optimization for supply chain network design under uncertainty." Computers and Industrial Engineering 85: $145-156$.

Yilmaz Balaman, Ş., and H. Selim. 2014. "A fuzzy multiobjective linear programming model for design and management of anaerobic digestion based bioenergy supply chains." Energy 74 (C): 928-940.

Yongheng, J., M.A. Rodriguez, I. Harjunkoski, and I.E. Grossmann. 2014. "Optimal supply chain design and management over a multi-period horizon under demand uncertainty. Part II: A Lagrangean decomposition algorithm." Computers and Chemical Engineering 62: 211224.

You, F., and I.E. Grossmann. 2008. "Mixed-integer nonlinear programming models and algorithms for large-scale supply chain design with stochastic inventory management." Industrial and Engineering Chemistry Research 47 (20): 7802-7817.

You, F., and I.E. Grossmann. 2009. "Optimal Design of Large-Scale Supply Chain with MultiEchelon Inventory and Risk Pooling under Demand Uncertainty." Computer Aided Chemical Engineering 26: 991-996.

You, F., and I.E. Grossmann. 2010. "Integrated multi-echelon supply chain design with inventories under uncertainty: MINLP models, computational strategies." AIChE Journal 56 (2): 419-440.

You, F., and I.E. Grossmann. 2011. "Balancing responsiveness and economics in process supply chain design with multi-echelon stochastic inventory." AIChE Journal 57 (1): 178-192.

Zahiri, B., S. Ali Torabi, M. Mohammadi, and M. Aghabegloo. 2018. "A multi-stage stochastic programming approach for blood supply chain planning." Computers and Industrial Engineering 122: 1 - 14 .

Zeballos, L.J., C.A. Méndez, A.P. Barbosa-Povoa, and A.Q. Novais. 2014. "Multi-period design and planning of closed-loop supply chains with uncertain supply and demand." Computers and Chemical Engineering 66: 151-164.

Zhang, Yong, and Yunjian Jiang. 2017. "Robust optimization on sustainable biodiesel supply chain produced from waste cooking oil under price uncertainty." Waste Management 60: 329 - 339. Special Thematic Issue: Urban Mining and Circular Economy.

Zokaee, S., A. Jabbarzadeh, B. Fahimnia, and S.J. Sadjadi. 2017. "Robust supply chain network design: an optimization model with real world application." Annals of Operations Research 257 (1-2): 15-44. 